\title{
SRY-Box Containing Gene 17 Regulates the Wnt/ $\beta$-Catenin Signaling Pathway in Oligodendrocyte Progenitor Cells
}

\author{
Li-Jin Chew, ${ }^{1}$ Weiping Shen, ${ }^{1}$ Xiaotian Ming, ${ }^{1}$ Vladimir V. Senatorov Jr, ${ }^{1}$ Hui-Ling Chen, ${ }^{1}$ Ying Cheng, ${ }^{1}$ Elim Hong, ${ }^{1}$ \\ Susan Knoblach, ${ }^{2}$ and Vittorio Gallo ${ }^{1}$ \\ ${ }^{1}$ Center for Neuroscience Research, and ${ }^{2}$ Center for Genetic Medicine Research, Children's Research Institute, Children's National Medical Center, \\ Washington, DC 20010
}

\begin{abstract}
The SRY-box (Sox) transcription factors regulate oligodendrocyte differentiation, but their signaling targets are largely unknown. We have identified a major signal transduction pathway regulated by Sox containing gene 17 (Sox17) in the oligodendrocyte lineage. Microarray analysis in oligodendrocyte progenitor cells (OPCs) after Sox 17 attenuation revealed upregulated genes associated with cell cycle control and activation of the Wingless and integration site $(\mathrm{Wnt}) / \beta$-catenin pathway. Sox17 knockdown also increases the levels of cyclin D1, Axin2, and activated $\beta$-catenin. In OPCs, the expression pattern of Sox17, cyclin D1, and secreted Frizzled-related protein-1 in the presence of platelet-derived growth factor (PDGF) was coordinately accelerated by addition of thyroid hormone, indicating differentiation-induced regulation of Sox17 targets. In developing white matter, decreased total $\beta$-catenin, activated $\beta$-catenin, and cyclin D1 levels coincided with the peak of Sox 17 expression, and immunoprecipitates showed a developmentally regulated interaction among Sox17, T-cell transcription factor 4, and $\beta$-catenin proteins. In OPCs, PDGF stimulated phosphorylation of glycogen synthase $3 \beta$ and the Wnt coreceptor LRP6, and enhanced $\beta$-catenin-dependent gene expression. Sox17 overexpression inhibited PDGF-induced TOPFLASH and cyclin D1 promoter activity, and decreased endogenous cyclin D1, activated $\beta$-catenin, as well as total $\beta$-catenin levels. Recombinant Sox17 prevented Wnt3a from repressing myelin protein expression, and inhibition of Sox17-mediated proteasomal degradation of $\beta$-catenin blocked myelin protein induction. These results indicate that Sox17 suppresses cyclin D1 expression and cell proliferation by directly antagonizing $\beta$-catenin, whose activity in OPCs is stimulated not only by Wnt3a, but also by PDGF. Our identification of downstream targets of Sox17 thus defines signaling pathways and molecular mechanisms in OPCs that are regulated by Sox17 during cell cycle exit and the onset of differentiation in oligodendrocyte development.
\end{abstract}

\section{Introduction}

The maturation of oligodendrocyte progenitor cells (OPCs) to myelinating oligodendrocytes requires the synchronized expression of numerous genes that coordinate each phase of lineage progression (Baumann and Pham-Dinh, 2001; Levine et al., 2001). In OPCs, the transition between proliferation and differentiation (Casaccia-Bonnefil and Liu, 2003) represents a critical control point in development. Although modulators of cyclin-dependent kinases have been identified as crucial regulators of this transition (Casaccia-Bonnefil et al., 1999;

Received July 1, 2011; accepted Aug. 5, 2011.

Author contributions: L.-J.C., W.S., X.M., and V.G. designed research; L.-J.C., W.S., X.M., V.V.S., H.-L.C., Y.C., E.H., and S.K. performed research; L.-J.C., W.S., X.M., V.V.S., H.-L.C., Y.C., E.H., and S.K. analyzed data; L.-J.C., W.S., and V.G. wrote the paper.

This work was supported by NIH Grant R01NS056427 (V.G.), National Multiple Sclerosis Society Grants RG3712A1 (V.G.) and RG3954A1/2 (L.-J.C.), European Leukodystrophy Association Research Foundation Grant ELA 2007-021C (V.G.), and NIH Intellectual and Developmental Disabilities Research Centers Grant P30HD40677 (V.G.). We thank Dr. Klaus-Armin Nave, Max Planck Institute for Experimental Medicine, Gottingen, Germany, for CNP-Cre mice; Dr. Edith Wang, University of Washington School of Medicine, for her gift of the human cyclin D1 Luc reporter plasmid; Dr. Glyn Dawson, University of Chicago, for the gift of human oligodendroglioma cells; and Drs. Lixin Kan and John Kessler, Northwestern University, for the $\beta$-catenin expression plasmid. We also thank Dr. David H. Rowitch, University of California, San Francisco, for discussion.

Correspondence should be addressed to Dr. Vittorio Gallo, Center for Neuroscience Research, Children's National Medical Center, 111 Michigan Avenue NW, Washington, DC 20010. E-mail: vgallo@cnmcresearch.org.

DOI:10.1523/JNEUROSCI.3343-11.2011

Copyright $\odot 2011$ the authors $\quad 0270-6474 / 11 / 3113921-15 \$ 15.00 / 0$
Ghiani and Gallo, 2001; Belachew et al., 2002), the mechanisms underlying the control of OPC differentiation remain incompletely understood.

High-mobility group (HMG) proteins are involved in oligodendrocyte lineage specification and cell maturation (Wegner, 2000, 2001). SRY-box (Sox) transcription factors contain an HMG DNA-binding domain, and regulate stem cell identity and function in multiple tissues (Gubbay et al., 1990; Schepers et al., 2002). Sox 17 activates endodermal target genes (Sinner et al., 2004), and is required for the formation of endoderm (Hudson et al., 1997; Kanai-Azuma et al., 2002; Yasunaga et al., 2005) and vascular endothelium (Matsui et al., 2006). Sox 17 also plays an important role in the maintenance of fetal and neonatal hematopoietic stem cells (Kim et al., 2007). Sox 8 , Sox 9 , and Sox 10 are required for oligodendrocyte development and maturation (Stolt et al., 2004, 2006; Finzsch et al., 2008), but their mechanisms of action in OPCs are still largely undefined. A postnatal role for Sox17 in oligodendrocyte development was previously described by our laboratory (Sohn et al., 2006). Sox17 expression is temporally correlated with that of multiple myelin genes in developing oligodendroglial cells, and Sox17 stimulates the myelin basic protein (MBP) promoter (Sohn et al., 2006). Loss-of-function and gain-of-function studies in OPCs have indicated that Sox17 expression is required for lineage progression, and that Sox 17 
A
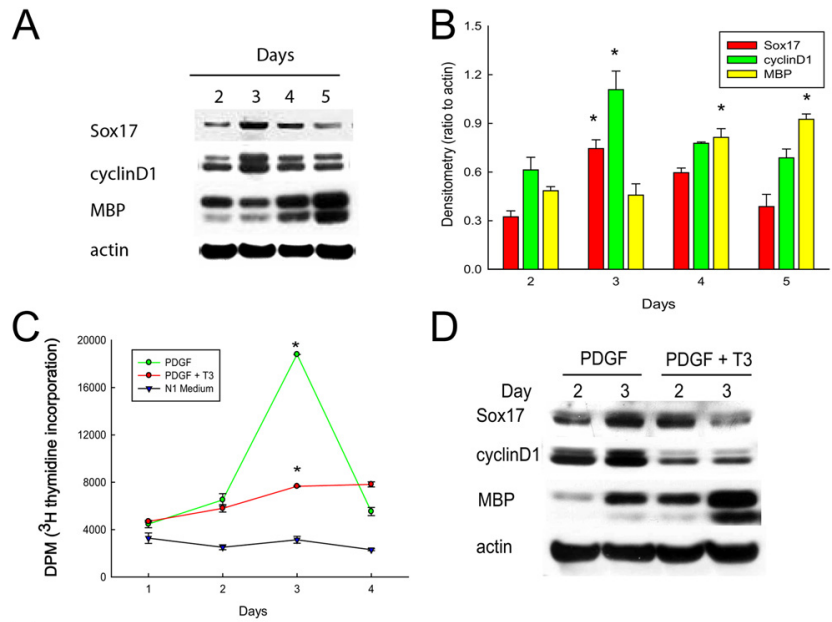

D

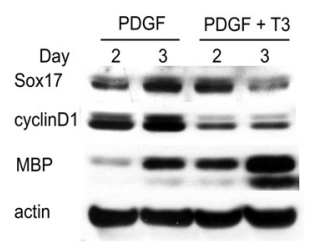

E

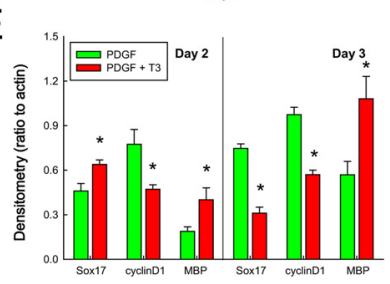

$F$

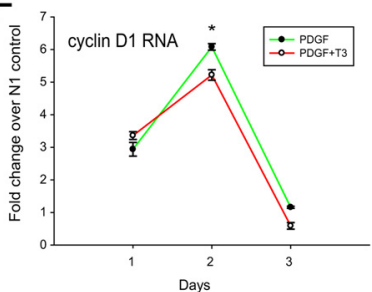

Figure 1. Regulation of Sox17, cyclin D1, and MBP expression in proliferating OPCs in culture. $\boldsymbol{A}$, Representative Western blot comparing Sox17, cyclin D1, and MBP expression and regulation in 0 PCs maintained in PDGF ( $P ; 10 \mathrm{ng} / \mathrm{ml})$ for $2-5 \mathrm{~d}$. B, Levels of expression of Sox 17, cyclin D1, and MBP with time in culture (days) after densitometric analysis of Western blots and normalization with $\beta$-actin values. ${ }^{*} p<0.01$ versus respective normalized values at day 2 , one-way ANOVA, Tukey's test. Values are mean \pm SEM of three experiments. $\boldsymbol{C}$, Proliferation assays with OPCs cultured in the presence and absence of thyroid hormone $(\mathrm{T} 3 ; 30 \mathrm{ng} / \mathrm{ml})$ in DMEM medium containing 1\% FBS, in 96-well culture plates (4 wells for each treatment) and incubated at $37^{\circ} \mathrm{C}$ in humidified air with $5 \% \mathrm{CO}_{2}$ for $1-4 \mathrm{~d}$. One microcurie of [ ${ }^{3} \mathrm{H}$ ]thymidine was added to each well, and cells were cultured for another $16 \mathrm{~h}$. Mean and SD of scintillation counts from four wells are shown. These results are representative of two separate experiments. ${ }^{*} p<0.01$ versus $\mathrm{N} 1$ medium, one-way ANOVA, Tukey's test. $\boldsymbol{D}$, Representative Western blot comparing Sox17, cyclin D1, and MBP expression in OPCs maintained in PDGF (P; $10 \mathrm{ng} / \mathrm{ml}$ ) or PDGF plus T3 (30 ng/ml) for 2-3 d. E, Quantification of Sox 17, cyclin D1, and MBP protein levels by densitometry and following normalization with $\beta$-actin. $\boldsymbol{F}$, Real-time $\mathrm{PCR}$ analysis of changes in cyclin D1 RNA following exposure to PDGF or P+T3. Data presented are mean \pm SEM from three independent experiments, showing fold change relative to respective $\mathrm{N} 1$ controls without PDGF after 1,2 , and 3 d in culture. ${ }^{*} p<0.05$ versus PDGF control at $2 \mathrm{~d}$, Students unpaired $t$ test.

promotes OPC cell cycle exit and differentiation (Sohn et al., 2006), but the molecular mechanisms by which Sox17 regulates OPC development have not been defined.

Wnt (Wingless and integration site) factors are secreted glycoproteins Which direct cell proliferation, polarity, and fate decisions during embryonic development. The best studied Wnt pathway, canonical Wnt signaling, functions through $\beta$-catenin (MacDonald et al., 2009). Wnt signaling promotes self-renewal of neural stem and progenitor cells, and is active prenatally in the dorsal spinal cord and subventricular zone of the CNS (Shimizu et al., 2005; Kalani et al., 2008). Canonical Wnt signaling activates nuclear translocation of $\beta$-catenin, resulting in the expression of Wnt target genes. While $\beta$-catenin signaling occurs during oligodendrocyte development, constitutive Wnt signaling has been shown to inhibit the differentiation of OPCs (Shimizu et al., 2005; Feigenson et al., 2009). Furthermore, dysregulation of Wnt $-\beta$-catenin signaling in OPCs results in pathological consequences (Fancy et al., 2009).

Table 1. List of genes regulated by Sox17 siRNA in primary OPCs identified by microarray analysis

\begin{tabular}{llc}
\hline Gene symbol & Gene name & Fold change \\
\hline Upregulated & & \\
Cdc42 bpb & Cdc42-binding protein kinase $\beta$ & 5.06 \\
cyclin B & Cyclin B & 4.31 \\
Axin 2 & Axin 2 & 3.70 \\
cyclinD1 & Cyclin D1 & 3.44 \\
PAK-1 & P21-activated kinase-1 & 2.57 \\
Igf2r & Insulin-like growth factor 2 receptor & 2.06 \\
PAK-4 & P21-activated kinase-4 & 2.05 \\
Sipa1 & Signal-induced proliferation-associated gene 1 & 1.74 \\
Gpr30 & G-protein-coupled receptor 30 & 1.73 \\
Phactr1 & Phosphatase and actin regulator 1 & 1.56 \\
Mapk10 & Mitogen-activated protein kinase 10 & 1.51 \\
Downregulated & & \\
Sfrp4 & SFRP4 & -2.21 \\
Stap2 & Signal-transducing adaptor protein-2 & -1.61 \\
Kcnn1 & Potassium intermediate/small conductance calcium- & -1.48 \\
& activated channel, subfamily N, member 1 & \\
Sfrp1 & SFRP1 & -1.46 \\
Kcnk4 & Potassium channel, subfamily K, member 4 & -1.45 \\
P27 (Kip1) & Cyclin-dependent kinase inhibitor & -1.42 \\
\hline
\end{tabular}

Genes regulated by Sox 17 siRNA in primary rat OPCs. Summary of microarray gene expression data obtained after transfection of Sox17 siRNA in OPCs. Cells were maintained in PDGF throughout the experiment, and samples were collected $48 \mathrm{~h}$ after removal of transfection complexes. Following recovery and extraction, amplified cRNA was hybridized with Affymetrix Rat Expression array. Data are averaged from three independent sets of samples, and selected genes showing statistically significant changes are presented. $p<0.05$ versus mock-transfected cells, unpaired Student's $t$ test. These genes were selected through Ingenuity pathway analysis.

In this study, we define signaling pathways regulated by Sox 17 in OPCs, and show that Sox17 antagonizes the Wnt $/ \beta$-catenin pathway, which is also stimulated by the mitogen PDGF. We provide evidence that the developmental regulation of Sox $17-\beta$ catenin interaction is consistent with its role in the control of OPC cell cycle exit and differentiation.

\section{Materials and Methods}

Antibodies. The following antibodies were used in Western blot: antirecombinant Sox17 antiserum (1:2000; gift from Y. Kanai, University of Tokyo, Tokyo, Japan); mouse anti- $\beta$-catenin ( $1: 1000$; Western blotting and immunoprecipitation, 1:500 in immunocytochemistry; BD Biosciences); goat $\beta$-catenin (1:1000; R\&D Systems); anti-active $\beta$-catenin (ABC; 1:1000); proteolipid protein (PLP)/DM20 (1:1000); T-cell transcription factor 4 (TCF4) (1:1000); anti-actin (1:5000); normal mouse IgG polyclonal (Millipore); anti-cyclin D1, proliferating cell nuclear antigen (PCNA), p27Cip/Kip (1:800; Santa Cruz Biotechnology); anti-p21activated kinase 1 (PAK1) (1:1000); anti-phospho-PAK1 (1:1000), antip44/p42 mitogen-activated protein kinase (MAPK) (Erk1/2) (1:1000); anti-phospho glycogen synthase kinase-3 $\beta$ (GSK3 $\beta])(1: 1000$ in Western blotting, 1:400 in immunocytochemistry); anti-phospho-LRP6 (1: 1000 in Western blotting, 1:500 in immunocytochemistry); antiphospho $\beta$-catenin (S33/37/T41) (1:1000); anti-HA (1:1000 in Western blotting, 1:200 in immunocytochemistry) (Cell Signaling Technology); anti-MBP and anti-2' $2^{\prime}$ cyclic nucleotide $3^{\prime}$ phosphodiesterase (CNPase) (1:1000; Covance); anti-cdc42 binding protein kinase $\beta$ (1:100), anti-c-myc (1:1000); anti-secreted Frizzled-related protein-1 (SFRP1); Axin2 (1:500; Abcam); and anti-cdc42 (1:500; Cell Biolabs).

Cell cultures. Purified rat cortical OPC cultures were prepared as previously described from E20 Sprague Dawley rats, using a standard experimental protocol (McCarthy and de Vellis, 1980) with slight modifications (Ghiani et al., 1999a,b). OPCs were isolated by differential plating following overnight shaking of flasks of mixed glia. OPCs were plated at a density of 500,000 cells per dish on polyornithine-coated 60 $\mathrm{mm}$ plastic Petri dishes and cultured in DMEM-N1 supplemented with $10 \mathrm{ng} / \mathrm{ml}$ PDGF (human AB, heterodimer form; Millipore), unless otherwise stated. When used, basic fibroblast growth factor (bFGF) was added at a final concentration of $10 \mathrm{ng} / \mathrm{ml}$ in DMEM-N1. Human oligo- 
A

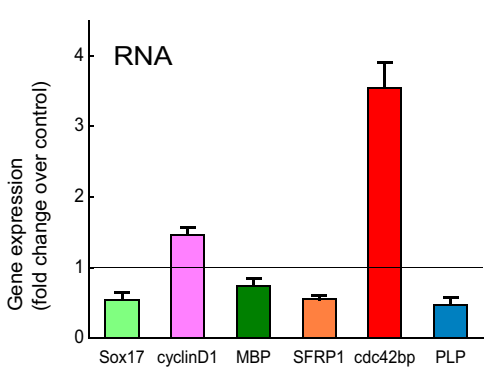

C
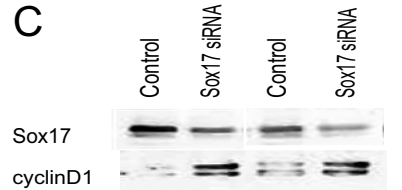

MBP

P-PAK1

IP: PAK1

IB: P-PAK

actin

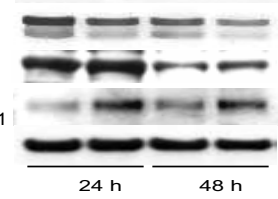

$\mathrm{D}$

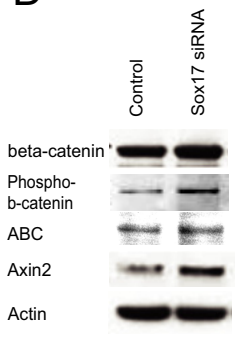

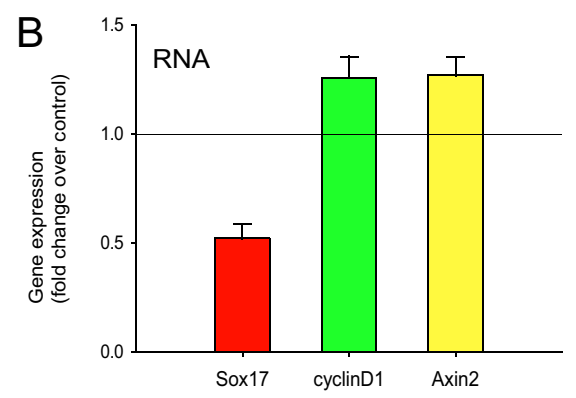

E

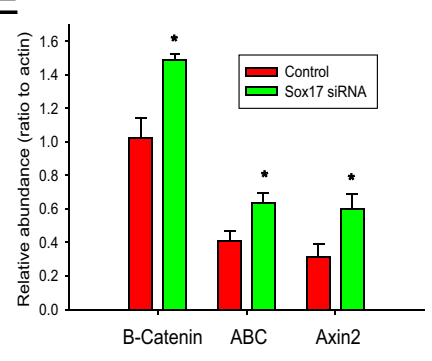

Figure 2. Effect of Sox17 knockdown on target gene expression in OPCS. A, After transfection of Sox17 siRNA in purified OPCS and culture for a further $24 \mathrm{~h}$ in the presence of PDGF, total RNA was extracted and analyzed by real-time PCR. B, Targeted Sox17 ablation in CNP-expressing cells of the developing WM leads to upregulation of target genes in P10 mice. The expression of Sox17 and indicated factors was analyzed by real-time PCR. Values shown are significantly different from controls (Student's $t$ test, $p<$ 0.05). C, D, Western blotting shows changes in MBP and $\beta$-catenin after Sox 17 knockdown in culture. In C, OPCs were transfected with Sox17 siRNA for 24 or $48 \mathrm{~h}$ before recovery in PDGF for a further $24 \mathrm{~h}$. P-PAK1 was detected in whole-cell extracts or after immunoprecipitation (IP) using a PAK1 antibody, followed by immunoblotting (IB) for P-PAK1. D, Western blot showing alteration of $\beta$-catenin levels by Sox17 siRNA. $E$, Densitometric quantitation showing changes in total $\beta$-catenin, $A B C$, and Axin2 proteins with Sox 17 siRNA. ${ }^{*} p<0.05$, Student's $t$ test. Data represent the mean \pm SEM of three experiments.

dendroglioma (HOG) cells were maintained in DMEM with 10\% FBS, 2 $\mathrm{mm}$ L-glutamine, $100 \mathrm{U} / \mathrm{ml}$ penicillin, and $100 \mu \mathrm{g} / \mathrm{ml}$ streptomycin at $37^{\circ} \mathrm{C}$ in $5 \% \mathrm{CO}_{2}$. These cells have been reported to exhibit markers of immature oligodendrocytes such as CNPase and GalC, but not the astrocytic marker GFAP (Post and Dawson, 1992).

Loss-of-function studies. Double-stranded Sox17 small interfering RNAs (siRNA) were obtained from Ambion/Applied Biosystems. A combination of the following three Sox17 siRNA sequences was used: ID101960 sense, GAGCUAAGCAAGAUGCUAGtt and antisense, CUAGCAUCUUGCUUAGCUCtg; ID 69339 sense, GGCUGUUCAAAAAUUUCGGtt and antisense, CCGAAAUUUUUGAACAGCCtC; ID 101869 sense, GAACCCAGAUCUGCACAACtt and antisense, GUUGUGCAGAUCUGGGUUCtg. Purified OPCs (cultured in $60 \mathrm{~mm}$ dishes; $5 \times 10^{5}$ cells per dish) were treated with PDGF $(10 \mathrm{ng} / \mathrm{ml})$ for $36-40 \mathrm{~h}$ and then transfected in serum- and antibiotic-free DMEM-N1 medium with a 1:1:1 mixture of Sox17 siRNAs (final concentration, 45 nM) using Lipofectamine 2000 (Invitrogen) at an siRNA/Lipofectamine ratio of $20 \mathrm{pmol}: 1 \mu \mathrm{l}$ for 24 or $48 \mathrm{~h}$. Controls were mock transfected with Lipofectamine reagent. The medium was then replaced with fresh DMEM-N1 supplemented with PDGF (10 ng/ml), and the cells were harvested at 24 or $48 \mathrm{~h}$ for analysis. Double-stranded $\beta$-catenin siRNA was also obtained from Ambion/Applied Biosystems. The following two $\beta$-catenin siRNA sequences were combined: ID s136460 sense GACUACCUGUUGUGGUUAAtt and antisense UUAACCACAACAGGUAGUCca; ID s136458 sense CACUUGCAAUAAUUACAAAtt and antisense UUUGUAAUUAUUGCAAGUGag. The 1:1 mixtures of $\beta$-catenin siRNAs or control siRNAs (Ambion) were transfected overnight in antibiotic-free N1 medium with or without PDGF at a final total concentration of $80 \mathrm{~nm}$. In these experiments, cells were allowed to recover for $48 \mathrm{~h}$ before analysis by Western blotting.

Microarray analysis. Approximately 500,000 purified rat OPCs were homogenized in RNeasy Lysis Buffer (Qiagen) by passing the lysate through a 20 -gauge needle $(0.9 \mathrm{~mm}$ diameter $)$ six times. Total RNA was extracted following standard protocol of RNeasy Mini kit (Qiagen). Digestion of DNA was performed using DNase I (Ambion) followed by clean-up using RNeasy Macro kit. Doublestranded cDNA was synthesized from $0.3 \mathrm{~g}$ of total RNA with an oligo-dT primer containing T7 RNA polymerase promoter (Geneset) and SuperScript Choice system (Invitrogen). After clean-up by ethanol precipitation, the doublestranded cDNA was resuspended in $8 \mu \mathrm{l}$ of DEPC $\mathrm{H}_{2} \mathrm{O}$. The resulting double-stranded cDNA was purified via a Phase Lock Gel (Brinkman Instrument) followed by ethanol precipitation. Biotinylated cRNA was produced by in vitro transcription using BioArray HighYield RNA Transcript Labeling Kit (Enzo). cRNA was purified using a Qiagen RNeasy mini kit and then fragmented. Fifteen micrograms each of biotinylated the cRNA sample was hybridized to rat expression array 230A (12488 probe sets; Affymetrix) for $16 \mathrm{~h}$. Microarrays were washed and stained on the Affymetrix Fluidics Station 400 using instructions, and reagents were provided by Affymetrix. Staining images were read by using the Hewlett-Packard G2500A Gene Array Scanner, and raw intensity data were captured. The Affymetrix Microarray Suite 4.0 was used in the primary absolute analysis to calculate signal intensity from a single array and in-chip normalization to a target intensity of 800 . Probeset hybridization performance (16-20 perfect match and mismatch probe pairs per probe set) determines whether a transcript is reliably detected as "present" and eliminated most nonspecific cross-hybridization signals, as previously described (Chen et al., 2000; Bakay et al., 2002).

Data visualization and statistical analyses using GeneSpring Software (Stratagene) (Seo and Hoffman, 2006). Candidate probe sets showing changes were selected based upon those concordant in RMA and dChip algorithms with at least one present call and a Welch ANOVA $t$ test of $p<0.05$ compared with control, and a significant difference in gene expression. We also used the Ingenuity Pathway Analysis program (Ingenuity Systems) to define known protein-protein and gene-protein networks that involved the selected transcripts.

Real-time reverse-transcription PCR. Total RNA (500 ng) was used to synthesize cDNA using oligo-dT primer (Invitrogen) in a $20 \mu \mathrm{l}$ reaction. cDNA (1-2 $\mu \mathrm{l})$ was then used for real-time PCR in a $25 \mu \mathrm{l}$ reaction. Monoplex real-time PCR was conducted in a 96-well spectrofluorometric thermal cycler (ABI PRISM 7900 Sequence detector system; Applied Biosystems). Primers used for PCR are as follows: Sox17 forward, 5'-TATGGTGTGGG CCAAAGACGAA-3'; Sox 17 reverse, $5^{\prime}$-CCGCTTCTCTGCCAAG GTCAA-3'; cyclin D1 forward, 5' -CTTCAAGTGCGTGCAGAGGGAG-3'; cyclin D1 reverse, 5'-GTAGTTCATGG CCAGCGGGAAG-3'; Cdc42bp forward, 5'-GCCACTGCACGTCC TTGATGGT-3'; Cdc42bp reverse, 5' AGGCCTCTTGGACTGCTCAGGA-3'; SFRP-1 forward, 5'-TAAAGAATGGCGCCGACTGTC-3'; SFRP-1 reverse, 5' -TGGCTGTGAGC AAGTACTGGCT-3'; MBP forward, $5^{\prime}$-ATGGCATCACAGAAGA GACCCTCA-3'; MBP reverse, 5' -TAAAGAAGCGCCCGATGGAGTCAA3'; PLP forward, 5'-AGCGGGTGTGTCATTGTTTGGGAA-3'; PLP reverse, $5^{\prime}$-ACCATACATTCTGGCATCAGCGCA-3'; mouse Axin2 forward, 5'-CAGCCCTTGTGGTTCAAGCT-3'; mouse Axin2 reverse, 5' GGTAGATTCCTGATGGCCGTAGT-3'; $\beta$-actin forward, $5^{\prime}$-GAAG AGCTATGAGCTGCCTGAC- ${ }^{\prime}$; and $\beta$-actin reverse, $5^{\prime}$-AGGTCTTT ACGGATGTCAACGT- $3^{\prime}$. $\beta$-actin was used as an internal normalization control. The cycling parameters were as follows: $95^{\circ} \mathrm{C}, 45 \mathrm{~s} ; 58^{\circ} \mathrm{C}$ or $50^{\circ} \mathrm{C}$, $50 \mathrm{~s}$; and $72^{\circ} \mathrm{C}, 55 \mathrm{~s}$; and $40 \mathrm{cycles}$. Fluorescence was monitored during every PCR cycle at the annealing or extension step and during the post-PCR temperature ramp. Fold changes were then measured according to instructions of the manufacturer (Invitrogen). 
Generation and analysis of CNP promotertargeted Sox17 conditional knock-out mice. A targeting construct containing all five exons of the mouse Sox17 gene was generated by Ingenious Targeting Laboratory. In this construct, exons 4 and 5, which encode the entire Sox17 coding region, are flanked by LoxP sites, and the pGK-gb2 loxP/FRT Neo cassette lies 3' to exon 5. The construct was linearized and electroporated into ES cells, and positive clones were isolated. Resultant chimeric mice with the targeted Sox $17^{\text {flox }}$ conditional allele were obtained and bred with C57BL/6 mice to obtain heterozygous Sox $17^{\text {flox }}$ offspring. The Neo cassette, which is flanked by two FRT sites, was excised by breeding with transgenic "flipper" mice ubiquitously expressing FLP recombinase. These mice were crossed with C57BL/6 mice, resulting in neomycindeleted Sox $17^{f l o x}$ animals. Conditional Sox $17 \mathrm{mu}-$ tants were subsequently generated by crossing Sox $17^{\text {flox/flox }}$ mice with Sox $17^{\text {flox/flox }} ; \mathrm{CNP}-\mathrm{cre}^{\text {cre/+ }}$. The CNP-Cre knock-in mouse strain (LappeSiefke et al., 2003) is a kind gift from Dr. Klaus-Armin Nave (Max Planck Institute, Göttingen, Germany). The sequences of the PCR primers used to identify the conditional Sox17 mutants are as follows: recombined $\mathrm{KO}$ forward5' -CAGCCTTCCTATTTCCCCAAGAGG-3', recombined KO reverse- 5'-CTAGTGTCAGGGACTAGGAGGGAG-3'; internal control lox1 Forward-5'-CAG CCT TCC TAT TTC CCC AAG AGG-3'; internal control lox3 Reverse-5' CTG GTC GTC ACT GGC GTA TCC- $3^{\prime}$; Cre sequence cre Forward-5'-GCG GTC TGG CAG TAA AAA CTA TC-3'; cre Reverse-5' -GTG AAA CAG CAT TGC TGT CAC TT-3'. The mutant mice are viable, with apparently normal lifespans.

OPC proliferation assay. OPCs $\left(2.5 \times 10^{4}\right.$ cells/200 $\mu$ l of DMEM containing $1 \%$ fetal calf serum and $10 \mathrm{ng} / \mathrm{ml}$ PDGF) were cultured in 96-well culture plates for 1-4 d. Sixteen hours before cell harvest, $1 \mu \mathrm{Ci}\left[{ }^{3} \mathrm{H}\right]$ thymidine was added to each well. Cells were washed with PBS and incubated briefly with methanol. $\left[{ }^{3} \mathrm{H}\right]$ thymidine incorporation was determined by liquid scintillation counting after trichloroacetic acid precipitation.

Western blot. Cells cultures were washed twice in cold PBS and collected by scraping in PBS. The cell pellet was resuspended in $100 \mu \mathrm{l}$ of RIPA lysis buffer (10 mм HEPES, pH 7.9, 1 mm EDTA, pH 8.0, 150 mм $\mathrm{NaCl}, 1 \mathrm{~mm}$ DTT, 1 mm PMSF, $0.5 \mathrm{~mm}$ sodium vanadate, $1 \% \mathrm{NP}-40$ ) in $1.5 \mathrm{ml}$ Eppendorf tubes for $20 \mathrm{~min}$ on ice and then centrifuged at 12,000 $\mathrm{rpm}$ at $4^{\circ} \mathrm{C}$ for $15 \mathrm{~min}$. Dissected white matter (WM) tissue samples from P5, P18, and P30 wild-type C57Bl6 mouse brains were lysed with homogenizer in RIPA lysis buffer. Cell cytoplasmic protein was collected and quantified by bichinconic acid assay (BCA) (Pierce). Fifty micrograms of protein (for Sox17 detection) or 10-20 $\mu \mathrm{g}$ of protein (for other protein detection) from each lysate was mixed with $(4 \times)$ NuPAGE LDS Sample buffer (Invitrogen) and boiled for $5 \mathrm{~min}$. After electrophoresis on $4-12 \%$ NuPage Bis-Tris precast gel (Invitrogen), the proteins were transferred to Immobilon P membranes (Millipore). The membranes were blocked in freshly prepared PBS containing 5\% dry milk, or Tris-buffered saline (TBS) containing $5 \%(\mathrm{w} / \mathrm{v})$ bovine serum albumin (BSA) (for detection of phosphoproteins), and then were incubated with diluted primary antibody overnight at $4^{\circ} \mathrm{C}$. This was followed by washing three times with PBS or TBS containing $0.05 \%$ Tween 20. The membranes were incubated with a horseradish

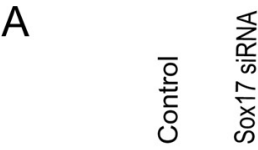

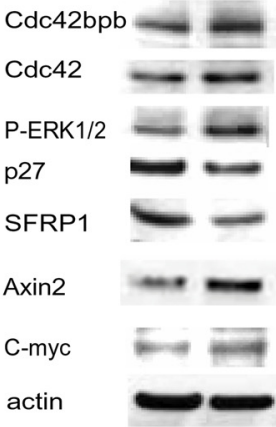

B

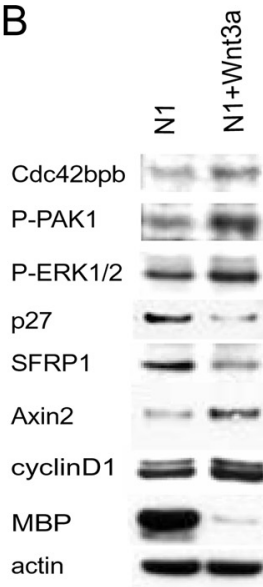

Figure 3. Regulation of Wnt pathway genes by Sox 17 in OPCS. A, Purified OPCs were transfected with Sox 17 siRNAs and allowed phosphorylated-ERK1/2, c-myc, and p27 was detected by Western blotting. B, OPCs were cultured in medium containing $1 \%$ FBS,

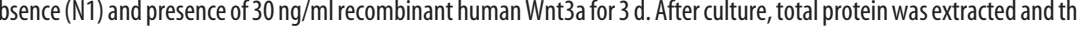
relationships between gene products found regulated by Sox17 siRNA, either at the RNA or protein levels. Upregulated gene products are represented in red, and downregulated products in blue. Solid arrows indicate stimulation, while bars indicate repression of activity. GEF, GTP exchange factor; DKK, Dickkopf; APC, adenomatous polyposis coli; PRK, protein tyrosine kinase; $\mathrm{GPCR}, \mathrm{G}$ protein-coupled receptor.

peroxidase-conjugated secondary antibody in PBS or TBS containing milk or BSA for $1 \mathrm{~h}$ at room temperature with agitation. After washing three times with PBS or TBS-0.05\% Tween 20, the membranes were incubated with SuperSignal Chemiluminescent Substrate Stable Peroxide Solution (Pierce) for 5 min and exposed to Biomax-MR film (Eastman Kodak)

Immunoprecipitation assays. OPCs cultured for $3 \mathrm{~d}$ under various conditions and mouse white matter tissue isolated at P5, P18, and P30 were lysed in RIPA lysis buffer containing protease inhibitors. Following BCA protein analysis, approximately $300-500 \mu \mathrm{g}$ of protein per sample was first precleared with 1/10 volume of protein G Sepharose beads (Millipore) at $4^{\circ} \mathrm{C}$ for $1 \mathrm{~h}$ with rotation. After pelleting the beads by centrifugation, the supernatants from these reactions were then incubated with 2 $\mu \mathrm{g}$ of primary antibody or control polyclonal mouse IgG at $4^{\circ} \mathrm{C}$ on an end-over-end rotator. After overnight incubation, protein G Sepharose beads (Millipore) were added at 1/10 total volume and incubated for an additional $2 \mathrm{~h}$ at $4^{\circ} \mathrm{C}$. The beads were then centrifuged, washed twice with RIPA buffer, and resuspended in Laemmli sample buffer. After boiling 
for $5 \mathrm{~min}$, the samples were resolved on $4-15 \%$ gradient SDS gels and analyzed by Western blotting.

Reporter assays. For transient transfection, OPCs were plated in N1 with $10 \mathrm{ng} / \mathrm{ml} \mathrm{PDGF}$ at $2.5 \times 10^{5}$ cells per well in 6-well poly-L-lysinecoated tissue culture dishes $1-2 \mathrm{~d}$ before transfection. Cells in $1.5 \mathrm{ml}$ of N1 + PDGF received $0.4 \mu \mathrm{g}$ of cyclin D1-luciferase reporter or TOPFLASH (Millipore) reporter plasmid, $0.8 \mu \mathrm{g}$ of Sox 17 expression vector, and $0.02 \mu \mathrm{g}$ of SV $40-\beta$-galactosidase in $500 \mu \mathrm{l}$ of $\mathrm{N} 1$ with $2.4 \mu \mathrm{l}$ of Lipofectamine 2000. For analysis with $\beta$-catenin expression vector, 0.4 $\mu \mathrm{g}$ each of $\beta$-catenin and CMVTnT vector or CMVTnTSox17 (Sohn et al., 2006) were cotransfected with $0.4 \mu \mathrm{g}$ of either cyclin D1-luciferase or TOPFLASH. For HOG cell transfections, HOG cells were plated in $10 \%$ FBS/DMEM at $3 \times 10^{4}$ per well in 12 -well plates $24 \mathrm{~h}$ before transfection in DMEM-N1 medium. The final concentrations per well of DNA and Lipofectamine 2000 used with HOG cells were identical to those for OPCs. After overnight incubation with the DNA-Lipofectamine complexes, the medium was replaced with $\mathrm{N} 1$ (for cotransfections with $\beta$-catenin expression vector), $\mathrm{N} 1+10 \mathrm{ng} / \mathrm{ml}$ PDGF, or 10\% FBS/DMEM for HOG cells, and harvested $48 \mathrm{~h}$ after the start of transfection. Transfected cells were collected in 150-200 $\mu$ l of reporter lysis buffer (Promega) and $50 \mu \mathrm{l}$ of lysate assayed for luciferase activity on a Turner 20/20n luminometer (Turner Biosystems). Luciferase activity expressed as relative light units was normalized with total protein content by BCA assay (Pierce) or $\beta$-galactosidase activity. For assays analyzing both TOPFLASH and FOPFLASH, OPCs in 6-well plates were transfected with either TOPFLASH or FOPFLASH in combination with CMVTnT vector, CMVTnTSox17, or the constitutively active mitogen-activated protein kinase kinase 1 (MEK1) pFC-MEK1 (Stratagene/Agilent), using the same concentrations and procedures as listed above. Following measurement of luciferase activities, results were normalized by protein or $\beta$-galactosidase and are reported as a ratio of TOPFLASH/FOPFLASH for any given treatment.

Immunocytochemistry. OPCs on glass coverslips were fixed with $4 \%$ paraformaldehyde solution in PBS for 15 min at room temperature and permeabilized with $0.1 \%$ Triton X-100 in PBS for 10 min before blocking with $10 \%$ goat serum in PBS for $1 \mathrm{~h}$. After washing, cells were incubated with primary antibodies overnight in a solution containing $2 \%$ goat serum in PBS. Following four washes with PBS, cells were incubated at room temperature with FITC- or rhodamine-conjugated secondary antibodies (diluted in $2 \%$ goat serum) for $2 \mathrm{~h}$. After washing with PBS, the coverslips were then inverted onto microscope slides with DAPI-containing Vectashield. Using a $40 \times$ objective, fluorescent images were collected with equivalent exposure settings between experimental groups.

Retroviral overexpression of Sox17. A full-length mouse Sox17 cDNA sequence was used to generate the retroviral expression construct. The CMV promoter sequence was added to pMXs-IRES-GFP (Cell Biolabs) to generate pMXs-CMV-IRES-GFP. HASox17 was then inserted as a direct fusion with an N-terminal HA epitope tag into the XhoI site between the CMV promoter and IRES of the pMXs-CMV-IRES-GFP. The plasmid lacking the Sox17 insert, but carrying the CMV promoter was used to generate control GFP-expressing retrovirus. Both retroviral plasmids are replication incompetent. To generate retrovirus stocks, Plat-GP 293 packaging cells (Cell Biolabs) were transfected with each retroviral plasmid along with an equal amount of PVSVG, which expresses the VSV glycoprotein as a pantropic retrovirus receptor. Cells were transfected in T75 flasks at $75-85 \%$ confluency with Lipofectamine 2000 in OptiMem (Invitrogen) containing $10 \mu \mathrm{g} / \mathrm{ml}$ blasticidin. Lipofectamine 2000 was added at $2.2 \mu \mathrm{l} / \mu \mathrm{g}$ DNA. Each flask was transfected with $4 \mu \mathrm{g}$ of retroviral plasmid DNA and $4 \mu \mathrm{g}$ of pVSVG. After $72 \mathrm{~h}$, the supernatant containing the packaged virions was filtered with a $0.45 \mu \mathrm{m}$ filter and concentrated using the ViraDuctin retrovirus transduction kit (Cell Biolabs) components Reagents A and B. Following centrifugation, the pellets were resuspended in $\mathrm{HBSS}$ and aliquots were stored at $-80^{\circ} \mathrm{C}$ for use as retroviral stocks. Viral titers assayed with NIH3T3 fibroblasts cells gave estimates of $\sim 1 \times 10^{6}$ colony-forming units/ml (Etxeberria et al., 2010). Equivalent titers were used for the different viral stocks. For infection of OPCs, cells were incubated with PDGF, and FGF2 was added at a final concentration of $10 \mathrm{ng} / \mathrm{ml}$ for $24 \mathrm{~h}$ before addition of retroviral stock. Following overnight incubation with diluted retroviral stock, the cells
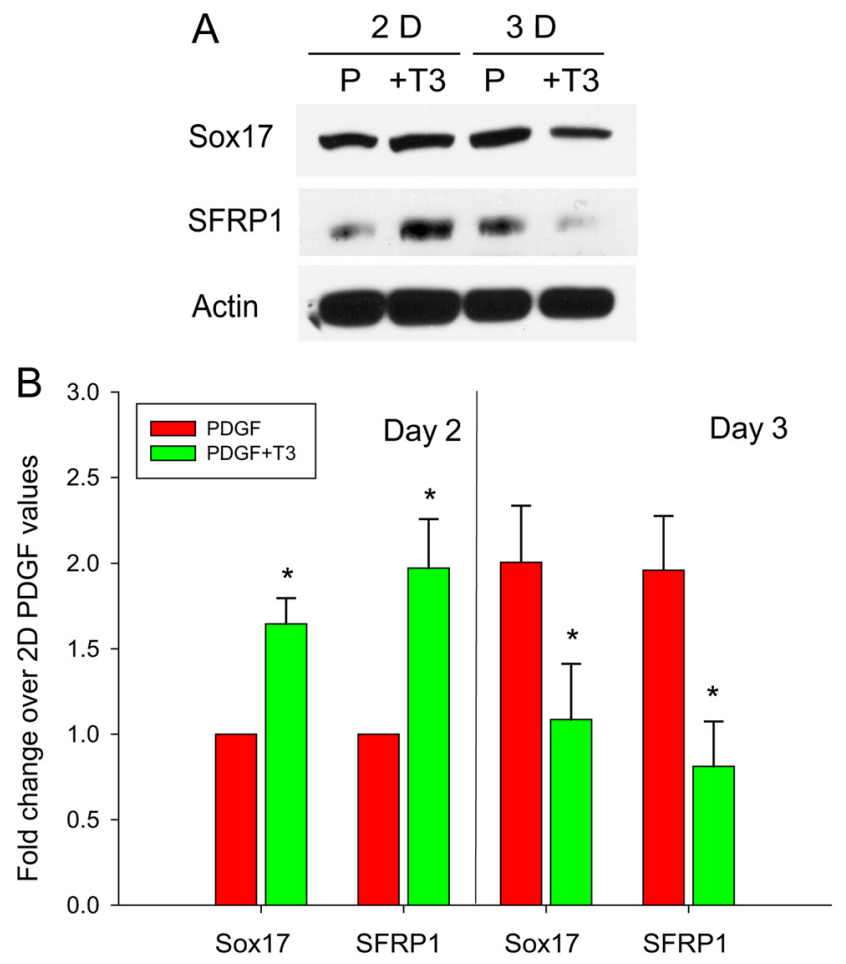

Figure 4. Thyroid hormone regulates Sox 17 and SFRP1 in OPCS. A, Representative Western blot comparing Sox17, cyclin D1, and MBP expression and regulation in OPCs maintained in PDGF (P; $10 \mathrm{ng} / \mathrm{ml})$ or PDGF plus thyroid hormone (+T3; $30 \mathrm{ng} / \mathrm{ml})$ for $2 \mathrm{~d}(2 \mathrm{D})$ to $3 \mathrm{~d}$ (3D). The Sox 17 blot from Figure 1 was reproduced for reference. $\boldsymbol{B}$, Densitometric quantitation of Western blots reveals an upregulation of both Sox 17 and SFRP 1 by PDGF alone on day 3 , as well as an upregulation by $\mathrm{T} 3$ on day $2 .{ }^{*} p<0.05$ versus PDGF values, unpaired Student's $t$ test. Data represent mean \pm SEM of three independent experiments, after normalizing against actin and expression as relative abundance for each protein over their respective values at $2 \mathrm{~d}$ in PDGF.

were rinsed twice with HBSS before and after incubation with diluted Reagent C (ViraDuctin retrovirus transduction kit; Cell Biolabs). Growth medium was replaced after the washes, and cells were assayed by immunocytochemistry, Western blotting, qPCR, or MTT reduction 48-72 post-transduction.

MTT reduction assay. OPCs were plated in poly-L-lysine-coated 12well dishes at 70,000 cells/well in $1 \mathrm{ml}$ of $\mathrm{N} 1+0.5 \%$ FBS medium containing PDGF + bFGF at $10 \mathrm{ng} / \mathrm{ml}$. Following viral transduction, medium was replaced with $\mathrm{N} 1+0.5 \%$ FBS containing high glucose phenol-red DMEM supplemented with PDGF + FGF at $10 \mathrm{ng} / \mathrm{ml}$ for an additional 2 and $4 \mathrm{~d}$ before analysis. On the day of analysis, $100 \mu \mathrm{l}$ of MTT reagent (TACS MTT Proliferation assay; Trevigen) was added to each well, and dishes were incubated at $37^{\circ} \mathrm{C}$ for $2 \mathrm{~h}$ before addition of $500 \mu \mathrm{l}$ of detergent reagent to solubilize the crystals. Supernatants $(200 \mu \mathrm{l})$ were transferred to 96-well plates and read on a Molecular Devices ThermoMax 96-well plate reader using a test wavelength of $570 \mathrm{~nm}$. HOG cells were plated at $3 \times 10^{4}$ cells per well in 12 -well plates and treated with Wnt, PDGF, or SFRP1 at the time of plating. MTT assays on HOG cells were performed according to the methods for primary OPCs.

\section{Results}

Sox17 expression in cultured oligodendrocyte progenitor cells is correlated with cell proliferation and myelin protein expression

Our previous studies had indicated a role for Sox17 in downregulating OPC proliferation (Sohn et al., 2006). The rate of cell cycle progression through the G1 phase is, in large part, determined by the induction of cyclin D1, typically the rate-limiting step in the formation of cyclin D-Cdk4/6 complexes and the consequent 
sequestration of $\mathrm{Cdk}$ inhibitors. Since Ki-67 was found to be expressed at very low or undetectable levels in cells transfected with a Sox17 expression plasmid (Sohn et al., 2006), we hypothesized that the effects of Sox17 on OPC cell cycle exit may involve the regulation of proteins that are expressed during the G1 phase, namely, cyclin D1. Indeed, in many instances, the coregulation of Ki-67 and cyclin D1 has been demonstrated (Bahnassy et al., 2004; Su et al., 2006). To examine the relationship between Sox17 expression and proliferative changes in progenitor cell development, we performed a series of time course studies in cultured OPCs maintained in PDGF, which promotes proliferation and allows limited spontaneous cell differentiation. Western blotting in Figure $1 A, B$ shows that Sox 17 protein levels peak at day 3 , together with the peak of cyclin D1 protein, which then declines on day 4 . The rise of MBP expression follows this peak of Sox17 and cyclin D1 proteins, suggesting that cell cycle regulation is coincident with high levels of Sox17 expression.

To correlate the regulation of Sox17 with changes in cell proliferation at the onset of terminal differentiation, we performed another time course study to analyze the effect of thyroid hormone. Tri-iodothyronine (T3) is well established as a promoter of differentiation in progenitor cells, which inhibits cell proliferation in OPCs (Baas et al., 1997). Other studies have also found that thyroid receptor $\beta 1$ downregulates cyclin D1 expression (Porlan et al., 2008). We hypothesized that, if Sox17 was involved in cell cycle exit, the addition of $\mathrm{T} 3$ to a culture medium that promotes proliferation may enhance or accelerate the peak of Sox17 expression.

Figure $1 C$ shows the results of a representative ${ }^{3}[\mathrm{H}]$ thymidine incorporation assay, which indicates that OPC proliferation peaks at day 3 in PDGF, whereas this sharp rise in cell proliferation at day 3 was abolished by the presence of T3 (PDGF + T3). Importantly, in agreement with our prediction that $\mathrm{T} 3$ would alter Sox17 expression, Sox17 levels were found to be increased at an earlier time point (day 2) compared with PDGF alone, and declined by day 3 (Fig. 1D). Quantitative analysis also shows that Sox17 expression was found to peak at an earlier time point and decline more rapidly in the presence of thyroid hormone (Fig. 1E). The expected increase in MBP levels by T3 is clearly observed under these conditions (Fig. $1 D)$. In agreement with the proliferation assays, cyclin D1 levels were found to be lower in the presence of thyroid hormone. The reduction in cyclin D1 expression with T3 is also observed at the RNA level by real-time PCR (Fig. $1 F$ ), suggesting that transcriptional control of cyclin D1 expression contributes to T3-mediated regulation of cyclin D1 levels and cell cycle progression. Furthermore, the sharp decline in cyclin D1 RNA on day 3 under PDGF (Fig. $1 F$ ) coincides with the peak of
$B$
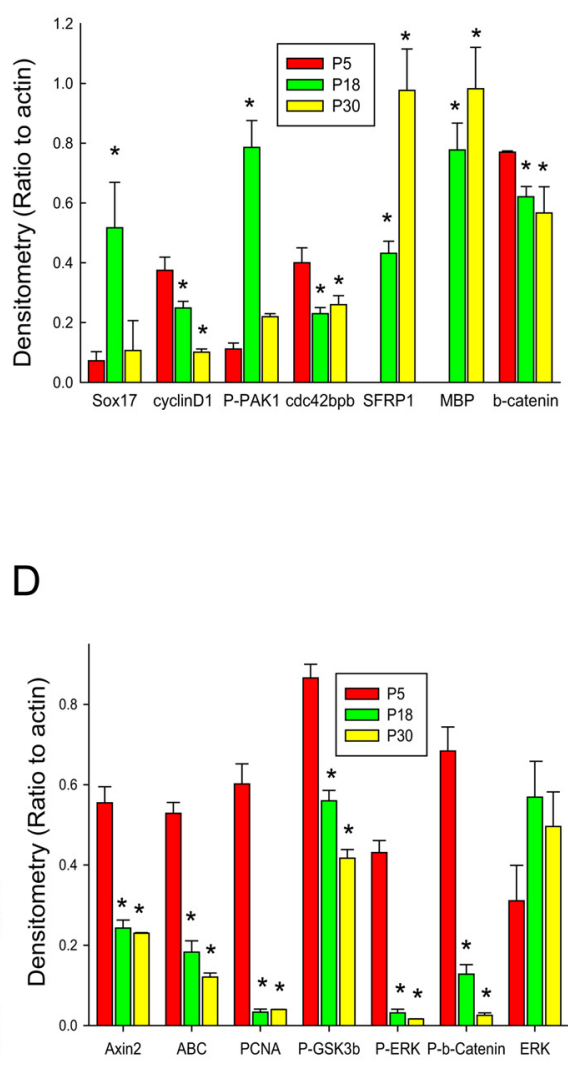

Figure 5. Maximal Sox17 expression in developing white matter coincides with OPC differentiation, and with a decline in cyclin D1 and ABC. Whole-cell proteins were extracted from P5, P18, and P30 wild-type C57B16 mouse subcortical white matter. $\boldsymbol{A}$ of Sox17 and some of its putative targets (cyclin D1, phospho-PAK1, SFRP1, cdc42bp, MBP, $\beta$-catenin, and activated $\beta$ shown in this representative blot. $\boldsymbol{B}$, Densitometric quantitation of the Western blot after normalization with $\beta$-actin. Each bar 作 $\beta$-actin. $\boldsymbol{B}, \boldsymbol{D},{ }^{*} p<0.05$ (one-way ANOVA, Tukey's test) versus respective P5 values. In $\boldsymbol{B}$, the values at P18 for cyclin D1 and SFRP1 were also significantly different from values at $\mathrm{P} 30$.

Sox 17 protein expression on day 3 (Fig. $1 A, B$ ). This decrease in cyclin D1 RNA on day 3 precedes the decline in its protein on day 4 and is consistent with a role for Sox17 in the transcriptional regulation of cell cycle exit. These data demonstrate that maximal Sox17 expression is associated with changes in cyclin D1 expression and cell cycle activity that accompany the onset of terminal OPC differentiation.

\section{Attenuation of Sox17 expression regulates multiple elements of the Wnt signaling pathway}

As the control of cyclin D1 gene expression would enable us to identify crucial regulators at the transition between OPC cell cycle exit and differentiation, we sought to establish cyclin D1 among the transcriptional targets of Sox17 action. It is known that the Sox HMG domain not only binds DNA directly, but also elicits a wide array of transcriptional responses through interaction with other transcription factors (Wissmüller et al., 2006). To define the molecular pathways underlying the developmental processes regulated by Sox 17 in OPCs, we undertook a broad screen of putative targets, both direct and indirect, of Sox17 fol- 
lowing attenuation of its expression with siRNA. Microarray analysis $(N=3)$ was performed using Affymetrix GeneChip rat expression array 230A (U34A) with RNA isolated from OPCs treated with Sox17 siRNA in the presence of PDGF. Previous studies have shown that under these transfection conditions Sox17 siRNA transfection did not affect cell viability (Sohn et al., 2006). Table 1 highlights some gene products found to be significantly regulated by Sox17 siRNA and that were selected through pathway analysis to be involved in the signaling and control of cell proliferation, morphogenesis, and development. Among these, a number of GTP exchange factors (data not shown), and cdc42 binding protein kinase $\beta$ (cdc42bpb) were upregulated by approximately fivefold following Sox17 knockdown, while the Wnt antagonist SFRP1 was downregulated by 1.5 -fold. The microarray screen was repeated with the Affymetrix Rat Gene 1.0 ST array, using scrambled siRNA-transfected OPCs as controls. This screen showed similar changes in the same pathways (e.g., cell proliferation and Wnt signaling, with cyclin D1 and Sipal at 1.3-fold increase), confirming the findings with different controls and GeneChip arrays. Subsequent real-time PCR assays demonstrated that Sox17 knockdown decreased SFRP1, MBP, and PLP expression (Fig. 2A), but upregulated cdc42bpb and cyclin D1 levels. In agreement with our previous findings (Sohn et al., 2006), these changes are indicative of inhibited OPC differentiation as well as increased cell cycle activity. Analysis of brain white matter tissue from mice in which Sox17 is specifically ablated in CNPase-expressing cells showed an increase in cyclin D1 RNA at P10 (Fig. 2 B). This was also accompanied by a similar change in Axin2 RNA, suggesting modulation of Wnt signaling activity. This observation provides in vivo evidence that loss of Sox17 in the developing white matter upregulates canonical Wnt/ $\beta$-catenin signaling and supports our findings in PDGF-treated cultured OPCs.

To further identify signaling proteins regulated by Sox17, Western blotting was performed on cultured OPCs transfected with Sox17 siRNA (Fig. 2C). These time course experiments confirmed that endogenous cyclin D1 protein was upregulated at 24 and $48 \mathrm{~h}$ following knockdown of Sox 17, with a consequent decrease in MBP levels. Additionally, we found that the level of phosphorylated PAK1 (P-PAK1) was elevated following Sox17 knockdown (Fig. 2C). Since cyclin D1 is a target of Wnt signaling, and PAK1 has been shown to be required for $\beta$-catenin activity in the nucleus (He et al., 2008; Sun et al., 2009), we investigated the possibility that the loss of Sox 17 might also regulate Wnt signaling through modulating $\beta$-catenin protein levels. As shown in Figure $2, D$ and $E$, Sox17 siRNA increased the levels of total $\beta$-catenin, Ser33/Ser37/Thr41-phosphorylated $\beta$-catenin, and $\mathrm{ABC}$, as well as its transcriptional target Axin2. Since $\beta$-catenin is believed to be destabilized by phosphorylation at Ser33/Ser37/ Thr41 (Aberle et al., 1997; Liu et al., 2002), it is possible that increased levels of Ser33-phosphorylated $\beta$-catenin may indicate decreased proteolytic turnover, ultimately leading to accumulation of ABC. These findings suggest that Sox 17 knockdown could relieve repression of the canonical $\beta$-catenin arm of the Wnt signaling pathway.

Since SFRP1 was found to be regulated by Sox 17 knockdown, its action at the level of the Frizzled receptor suggests that both canonical and noncanonical Wnt signaling pathways may be affected by Sox17 in OPCs. Figure $3 A$ shows that Sox17 indeed supports SFRP1 expression, and Sox17 loss also upregulates cdc42bpb/MRCK $\beta$, a downstream effector of cdc42. As a consequence of Rho-related changes, we also analyzed targets of PAK1 and Ras, namely, ERK (p44/p42) and p27, respectively, and
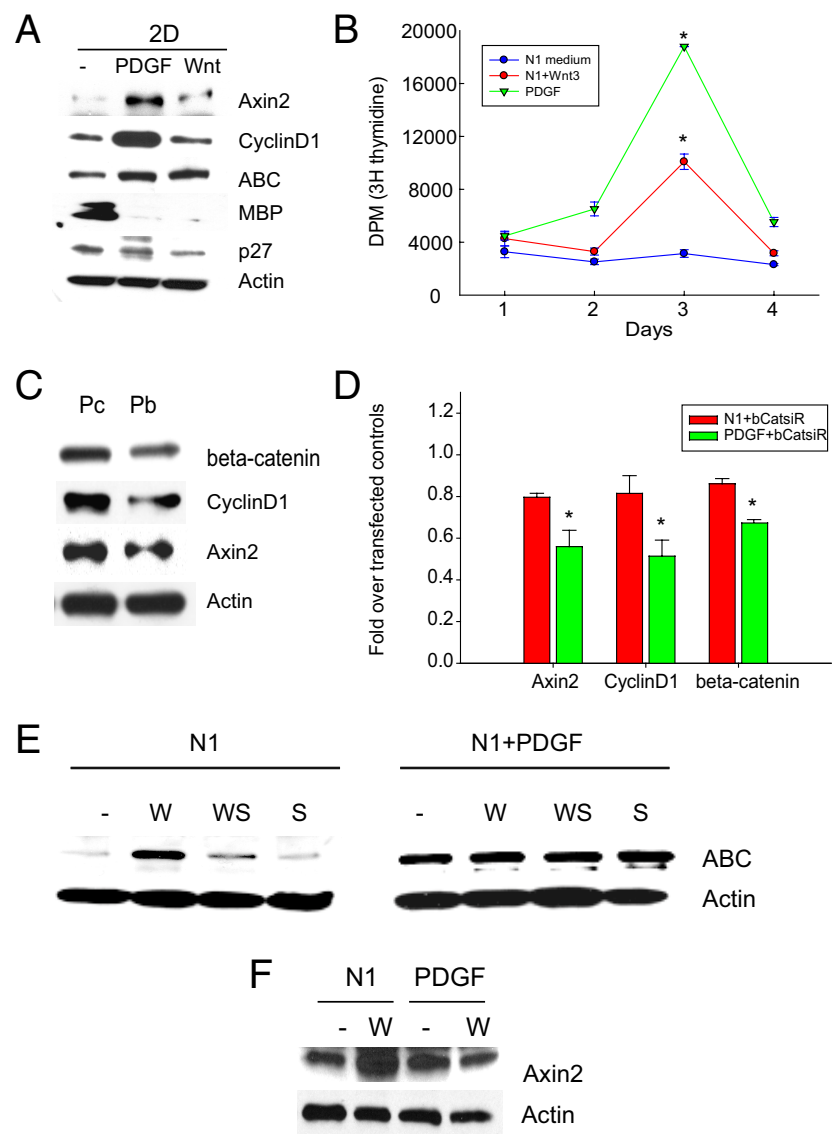

Figure 6. PDGF stimulates the Wnt $/ \beta$-catenin pathway in OPCs. $A$, Western blot analysis of MBP suppression, cyclin D1 induction, and $\beta$-catenin activation by PDGF and Wnt3a. Primary OPCs were treated with PDGF or $130 \mathrm{ng} / \mathrm{ml}$ recombinant Wnt 3a for $2 \mathrm{~d}$ (2D). $\boldsymbol{B}$, Thymidine incorporation assay comparing proliferation of primary rat OPCs treated with $10 \mathrm{ng} / \mathrm{ml} \mathrm{PDGF} \mathrm{or}$ $50 \mathrm{ng} / \mathrm{ml}$ human Wnt3a. One microcurie of [ $\left.{ }^{3} \mathrm{H}\right]$ thymidine was added to each well, and cells were cultured for a further $16 \mathrm{~h}$ before analysis. Means and SDs of counts from four wells are shown. The results are representative of two separate experiments. ${ }^{*} p<0.05$ versus $\mathrm{N} 1$ at $3 \mathrm{~d}$, one-way ANOVA, Tukey's test. C, Representative Western blot of cyclin D1 and Axin2 levels following transfection of $\beta$-catenin siRNA and recovery for $3 \mathrm{~d}$ in the presence of PDGF. PC, siRNA-transfected controls in PDGF; Pb, cells in PDGF transfected with $\beta$-catenin siRNA. $\boldsymbol{D}$, Densitometric quantitation of protein levels of Axin2, cyclin D1, and $\beta$-catenin following transfection with $\beta$-catenin siRNA (bCatsiR). OPCs were transfected with bCatsiR in the absence $(\mathrm{N} 1+b C a t s i R)$ and presence (PDGF + bCatsiR) of PDGF, and were allowed to recover in respective media for $3 \mathrm{~d}$ before analysis. Values shown are fold changes over respective control siRNAtransfected samples, either in N1 or PDGF, which were set at $1 .{ }^{*} p<0.05$ versus respective transfected controls in N1 or PDGF, Student's unpaired $t$ test. Data are mean \pm SEM of three independent experiments. $\boldsymbol{E}$, Inclusion of PDGF abolishes the effect of exogenous Wnt3a in the regulation of $A B C$. Western blot showing the effect of treatment for $3 \mathrm{~d}$ with $10 \mathrm{ng} / \mathrm{ml}$ Wnt3a (W) Wnt3a $+200 \mathrm{ng} / \mathrm{ml} \mathrm{SFRP1}$ (WS) or $200 \mathrm{ng} / \mathrm{ml} \mathrm{SFRP1}$ (S) in the absence (N1) and presence of $10 \mathrm{ng} / \mathrm{ml} \mathrm{PDGF}$. $\boldsymbol{F}$, Western blot showing the inclusion of $10 \mathrm{ng} / \mathrm{ml}$ PDGF abolishes the response of Axin2 to Wnt3a after treatment for $2 \mathrm{~d}$ with $10 \mathrm{ng} / \mathrm{ml}$ Wnt3a (W).

found that P-ERK and c-myc were both increased, while p27 was decreased after Sox17 knockdown (Fig. 3A). To compare these changes with Wnt pathway stimulation, OPCs were treated with Wnt3a, a member of the Wnt 1 family that is believed to predominantly activate the canonical Wnt pathway. Figure $3 B$ shows that, similar to Sox17 siRNA transfection, Wnt3a not only increased the levels of $\beta$-catenin targets cyclin D1 and Axin2, but also of the noncanonical pathway mediator $\mathrm{cdc} 42 \mathrm{bpb} / \mathrm{MRCK} \beta$, along with phosphorylated PAK1 and ERK. Consistent with our previous studies demonstrating the loss of cell cycle arrest following the knockdown of Sox17 (Sohn et al., 2006), other regulators of proliferation, such as the cyclin-dependent inhibitor p27Kip1 
and c-myc, were also downregulated and upregulated, respectively, after Wnt3a treatment.

As with Sox17 siRNA transfection (Fig. $3 A$ ), decreased levels of SFRP1 and MBP were also observed following Wnt3a exposure (Fig. 3B). Together, these results indicate that Sox 17 may function as a suppressor of Wnt signaling in OPCs. A diagram shown in Figure $3 C$ places the Sox17-modulated gene products (at the RNA and protein levels, and posttranslational levels) in putative signaling relationships with Wnt and other extracellular ligands. This pathway indicates that multiple factors involved in the control of cell cycle signaling are coordinately regulated by Sox17 siRNA.

\section{Regulation of SFRP1 by \\ thyroid hormone}

To determine whether an exogenous differentiation signal could modulate aspects of Wnt signaling in OPCs, we examined the effect of thyroid hormone on the regulation of SFRP1 and Sox17 expression in the presence of PDGF. The results in Figure $4, A$ and $B$, show that, as with Sox17, SFRP1 is clearly induced by PDGF after $3 \mathrm{~d}$. The inclusion of $\mathrm{T} 3$ resulted in an initial increase in SFRP1 at $2 \mathrm{~d}$, similar to that in Sox17. This was followed by a relative decline. The coordinate regulation is consistent with a function for Sox 17 in the control of SFRP1 expression and suggests that both proteins may play a role in modulating Wnt signaling during OPC development. Surprisingly, the total levels of ABC protein did not fall with $\mathrm{T} 3$ treatment over the same time course (data not shown), indicating a complex relationship among the canonical Wnt pathway, PDGF signaling, and T3 action. These observations nonetheless raise the distinct possibility that the induction of SFRP1 and Sox17 by PDGF could serve to antagonize canonical Wnt signaling under specific mitogenic conditions.

\section{Developmental regulation of putative Sox 17 targets in white matter}

Microarray and Western analysis of oligodendrocyte lineage cells FACS purified from CNP-EGFP mouse brains have previously demonstrated that Sox17 RNA and protein levels are developmentally regulated, showing a peak at P15 (Sohn et al., 2006). Consistent with these findings, we have verified that a peak of Sox17 protein expression is observed at P18 (Fig. 5A,B) using dissected subcortical WM tissue that includes the external capsule, cingulum, and corpus callosum. Sox 17 levels were very low at P5 and P30. Interestingly, coincident with the peak of Sox17 expression, the levels of cyclin D1 began to decrease at P18 and became almost undetectable by P30. The levels of total $\beta$-catenin and $\mathrm{cdc} 42 \mathrm{bpb} / \mathrm{MRCK} \beta$ also began to decline at P18. Importantly, the increased expression of MBP is observed together with that of Sox17 and SFRP1 at P18 (Fig. 5A,B), sug-
B

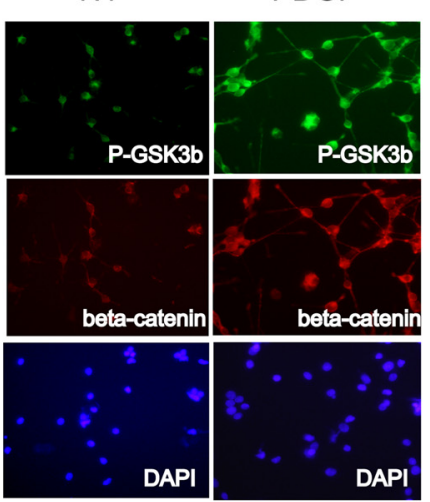

E
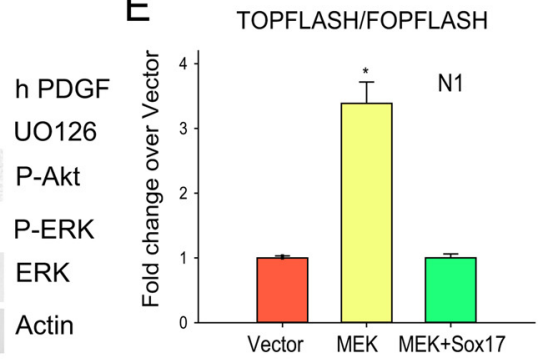

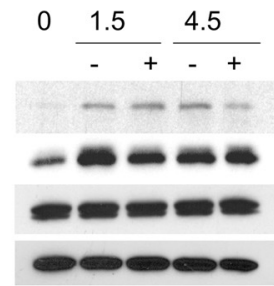

Figure 7. PDGF phosphorylates LRP6 via MEK, which promotes $\beta$-catenin/TCF-mediated transcription. $\boldsymbol{A}, \boldsymbol{B}$, Fluorescent microscope images of cells immunostained with antibodies against P-LRP6 (green) $(\boldsymbol{A})$, and Ser9-P-GSK3 $\beta$ (P-GSK3 $\beta$, green) and $\beta$-catenin (red) (B). Primary OPCs were allowed to rest in N1 basal medium for $24-36 \mathrm{~h}$ before stimulation with $10 \mathrm{ng} / \mathrm{ml}$ PDGF for shown are fold changes of TOPFLASH/FOPFLASH ratios over vector ratios using normalized TOPFLASH and FOPFLASH values for each condition. ${ }^{*} p<0.01$, one-way ANOVA, Tukey's post hoc test.

gesting that Sox17 is involved in the downregulation of Wnt signaling during the onset of active myelination.

To determine whether $\beta$-catenin-mediated pathways are regulated in relation to Sox17, we also analyzed the expression pattern of several $\beta$-catenin targets in the developing WM. Figure 5, $C$ and $D$, shows a clear downregulation of $\mathrm{ABC}$, Axin2, P-ERK, and proliferating cell nuclear antigen (PCNA) beginning at P18, indicating that changes in cell cycle activity of the WM accompany the developmental attenuation of $\beta$-catenin activity. Interestingly, these changes are observed in the presence of decreasing levels of Ser9-GSK3 $\beta$, suggesting increased GSK3 $\beta$ activity (Fig. $5 C, D)$.

\section{PDGF stimulates $\boldsymbol{\beta}$-catenin activity in OPCs}

Based on evidence that PDGF signaling is associated with $\beta$-catenin accumulation in liver carcinoma (Fischer et al., 2007) and that the activity of PDGF as a mitogen and migratory signal in smooth muscle as been shown to be mediated by GSK3 $\beta$ inhibition (Nunes et al., 2008), we hypothesized that Wnt/ $\beta$-catenin activation by Sox17 knockdown in our culture system may involve PDGF. The relationship between PDGF and $\mathrm{Wnt} / \beta$ catenin in developing neural cells is poorly understood, but it is possible that PDGF may stimulate cyclin D1 expression through 

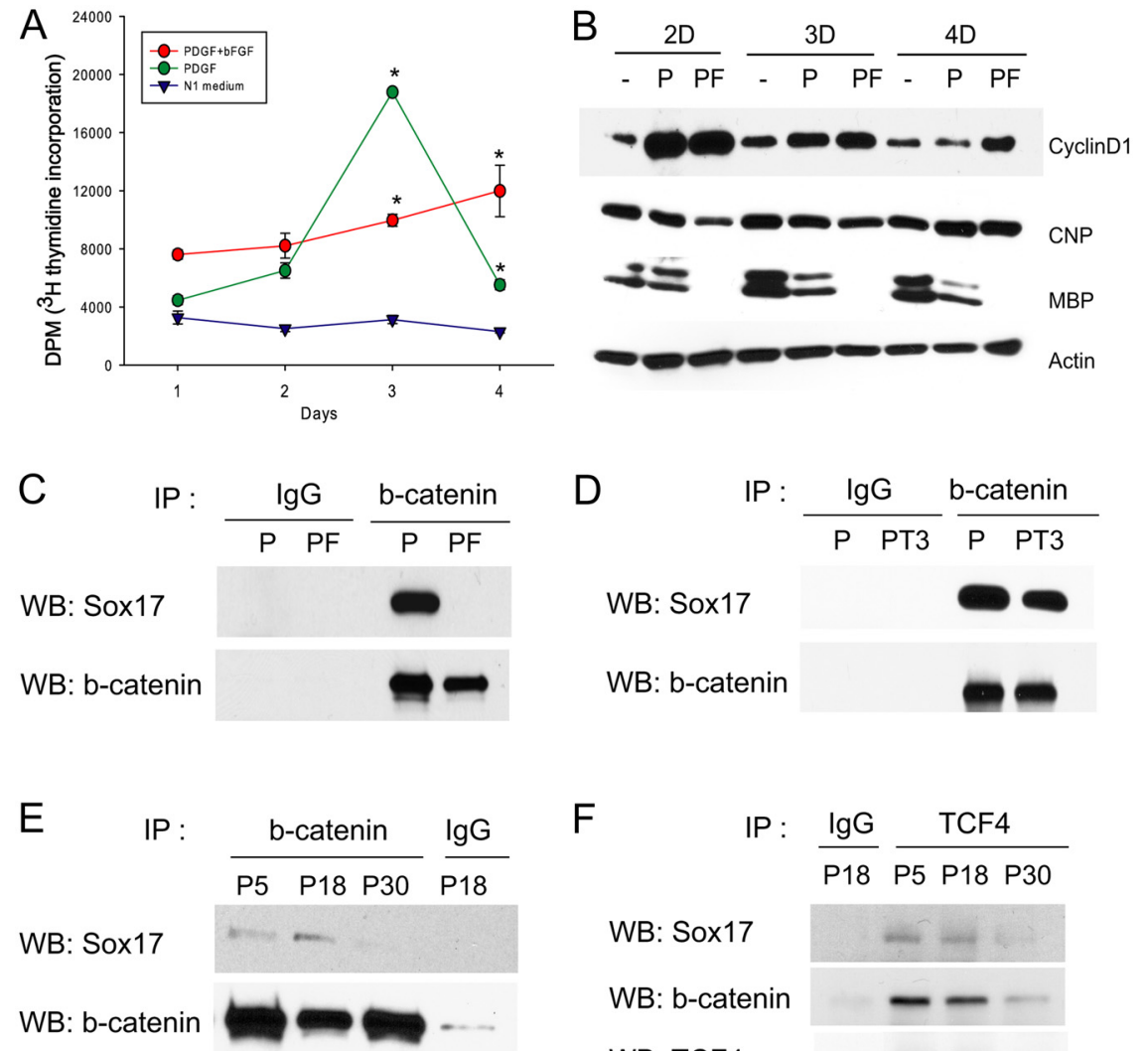

$\mathrm{F}$

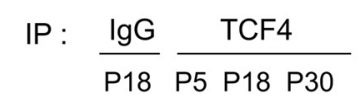

WB: Sox17
WB: b-catenin

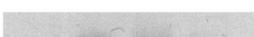

WB: TCF4

Figure 8. Sox17 associates with $\beta$-catenin under differentiating conditions. $\boldsymbol{A}$, Proliferation assays with OPCs cultured in N1 basal medium, $10 \mathrm{ng} / \mathrm{ml} \mathrm{PDGF}$, or $10 \mathrm{ng} / \mathrm{ml}$ PDGF $+\mathrm{bFGF}$ for up to $4 \mathrm{~d}$. Four wells were analyzed for each treatment per experiment. One microcurie of $\left[{ }^{3} \mathrm{H}\right]$ thymidine was added to each well during the final $16 \mathrm{~h}$ before analysis at each time point. Means and SDs of counts from four wells of a representative experiment are shown. ${ }^{*} p<0.05$ versus N1, one-way ANOVA, Tukey's test. The counts between $10 \mathrm{ng} / \mathrm{ml}$ PDGF (P) and $10 \mathrm{ng} / \mathrm{ml}$ each of PDGF + bFGF (PF), particularly at $3 \mathrm{~d}(3 \mathrm{D})$ and $4 \mathrm{~d}(4 \mathrm{D})$, were different from each other. $\boldsymbol{B}$, Western blot analysis of cyclin D1 and myelin proteins between conditions, which allow or inhibit OPC differentiation. Primary OPCs were cultured in N1 + P or PF for up to $4 \mathrm{~d}$. C, Immunoprecipitation of OPC lysates with $\beta$-catenin antibody shows association of $\beta$-catenin with Sox 17 in the presence of PDGF only, and not in the presence of bFGF. D, Immunoprecipitation of OPC lysates with $\beta$-catenin antibody shows association of $\beta$-catenin with Sox 17 in the presence of PDGF and thyroid hormone (PT3). In $\boldsymbol{C}$ and $\boldsymbol{D}$, samples were taken after $3 \mathrm{~d}$ of culture. Controls were samples immunoprecipitated with preimmune mouse $\lg G$. $\boldsymbol{E}$, Immunoprecipitation of lysates from the developing WM showing association of $\beta$-catenin with Sox17 at P5 and P18. F, Immunoprecipitation of WM lysates showing association of TCF4 with $\beta$-catenin and Sox17 at P5 and P18. As a negative control, P18 lysate was immunoprecipitated with preimmune mouse IgG in both $\boldsymbol{E}$ and $\boldsymbol{F}$. IP, immunoprecipitating antibody; WB, Western blot antibody.

$\beta$-catenin activation. Figure $6 \mathrm{~A}$ shows that PDGF and Wnt3a both increase the levels of $\mathrm{ABC}$, which in turn can promote the expression of its target genes, cyclin D1 and Axin2. After $2 \mathrm{~d}$ of exposure, both PDGF and Wnt3a also attenuate MBP expression compared with N1 controls. The differential stimulation of cyclin D1 by PDGF and Wnt3a prompted us to compare the two stimuli as mitogens. Proliferation assays (Fig. $6 B$ ) revealed PDGF to be a more potent mitogenic signal than Wnt3a, and suggested that the increased proliferation (Sohn et al., 2006) and cyclin D1 expression (Fig. $2 A, C$ ) following Sox17 knockdown in vitro were likely to involve PDGF signaling.

To determine whether PDGF-induced cyclin D1 expression was mediated by $\beta$-catenin activity, OPCs maintained in the presence of PDGF were transfected with siRNA against $\beta$-catenin. Western blotting showed that a $\sim 30 \%$ reduction in total $\beta$-catenin levels resulted in a clear reduction of cyclin D1 and Axin2 levels (Fig. 6C), indicating attenuated canonical Wnt signaling. In the absence of PDGF (N1 + bCatsiR) (Fig. 6D), $\beta$-catenin siRNA (bCatsiR) also produced a modest reduction in the levels of these proteins (probably due to the inclusion of insulin in the basal N1 medium), but a significantly greater reduction was observed in the presence of PDGF (Fig. 6D).

The notion that PDGF and Wnt may share the same signaling pathway is also supported by experiments in which Wnt3a and PDGF were combined. Figure $6 E$ shows that $\mathrm{ABC}$ protein levels increase when OPCs were treated with Wnt3a in basal medium N1. This response of $\mathrm{ABC}$ is lost when SFRP1 is combined with Wnt3a. However, in the presence of PDGF, Wnt3a no longer elicits an increase in ABC levels (Fig. 6E) and SFRP1 is ineffective. PDGF also induces an increase in Axin2 protein, and Wnt3a is also unable to mount an Axin2 response in the presence of PDGF (Fig. 6F). These results support a mechanism of cross talk so that PDGF activation of the Wnt pathway obscures or alters Wnt ligand responses along the canonical pathway.

The observation that SFRP1 failed to modulate $\mathrm{ABC}$ levels in PDGF-treated OPCs (Fig. 6E) suggests that PDGF may act at a level downstream from Frizzled receptor binding. The low-density lipoprotein receptor-related proteins (LRPs) 5 and 6 are coreceptors of Wnt ligands and LRP6 phosphorylation is important to $\beta$-catenin stabilization and pathway activation (Tamai et al., 2000). Phosphorylated LRP6 has been shown to interact with and directly inhibit GSK3 $\beta$ (Piao et al., 2008), so that PDGF may regulate both proteins. To investigate this possibility, we starved OPCs for $24-36 \mathrm{~h}$ in basal medium and exposed the cells to $10 \mathrm{ng} / \mathrm{ml}$ PDGF for $18 \mathrm{~h}$. We observed that PDGF stimulated the phosphorylation of LRP6 (Fig. 7A) and Ser9-GSK3 $\beta$ (Fig. 7B) in bipolar progenitor cells. In addition, the OPCs that immunostained with Ser9-GSK3 $\beta$ also showed increased levels of cellular $\beta$-catenin (Fig. 7B). Since PDGF also activates multiple MAPKs in OPCs (Chew et al., 2010), we determined whether changes in $\beta$-catenin and LRP6 phosphorylation were dependent upon mitogen-activated protein kinase/MEK. In these experiments, we pretreated OPCs with the MEK inhibitor UO126 before adding PDGF. Figure 7C shows that LRP6 phosphorylation, but not Ser9-GSK3 $\beta$, was MEK dependent. It is believed that inhibition of GSK3 $\beta$ by LRP6 occurs independently of P-Ser9 (Piao et al., 2008), so that PDGF likely stimulates GSK3 $\beta$ Ser9 phosphorylation in OPCs through a different pathway. Figure $7 D$ shows that PDGF stimulates the phosphorylation of Akt/ $\mathrm{PKB}$, which is capable of phosphorylating GSK3 $\beta$ Ser9 (Frame and Cohen, 2001). It is unclear why total $\beta$-catenin levels are unaffected by UO126, and we speculate that the dose of UO126 (1 $\mu \mathrm{M})$ may be too low to prevent $\beta$-catenin accumulation in wholecell lysates, despite downregulating P-ERK at $1.5 \mathrm{~h}$ (Fig. 7D). This dose, however, was sufficient to alleviate differentiation block imposed by high P-ERK levels without detectable change in cell 
proliferation (Chew et al., 2010) (L. J. Chew and V. Gallo, unpublished observations). Nonetheless, recombinant MEK clearly stimulates $\beta$-catenin/TCF transcriptional activity in the absence of mitogen, as detected by the TOPFLASH reporter assay (Fig. $7 E$ ). This observation is in agreement with a recent study showing cross talk between $\mathrm{Wnt} / \beta$-catenin signaling and recombinant mitogen-activated kinases (Červenka et al., 2011). When recombinant Sox17 is cotransfected with MEK, the increase in reporter activity is abolished (Fig. 7E), indicating that Sox17 antagonizes the transcriptional response of $\beta$-catenin/TCF to MEK activation. Together, these observations indicate that PDGF stimulates the phosphorylation of LRP6 through MEK activation, and GSK3 $\beta$ phosphorylation at Ser9 likely through Akt activation, both of which lead to $\beta$-catenin accumulation and cateninassociated transcriptional response.

\section{Sox17 interacts with $\beta$-catenin in developing OPCs}

The effects of $\beta$-catenin hyperactivity are known to be inhibitory to OPC development (Feigenson et al., 2009), but the mechanisms of $\beta$-catenin regulation by Sox 17 has not been explored in OPCs. The expression of Sox17 and ABC (Fig. 6A) in PDGFtreated OPCs hinted at the possibility that differential regulation of $\beta$-catenin function by Sox17 could underlie the difference between proliferative conditions permissive to differentiation and nonpermissive ones. We tested this hypothesis by analyzing the difference between PDGF and PDGF + bFGF as permissive and nonpermissive conditions, respectively. Figure $8 \mathrm{~A}$ shows that the inclusion of bFGF changes the proliferation pattern of OPCs as measured by a thymidine incorporation assay. This was most apparent after the third day of treatment. In PDGF alone, OPCs show a surge of proliferative activity that rapidly declines, while cells in PDGF + bFGF remained proliferative at day 4 (Fig. $8 A$ ). The prolonged proliferation stimulated by bFGF is supported by the enhanced expression of cyclin D1 after $4 \mathrm{~d}$, compared with untreated or PDGF-treated cells (Fig. 8 B). The growth factors also produced differential effects on myelin-specific proteins: in the presence of PDGF, bFGF showed a transient inhibitory effect on CNPase expression, but dramatically suppresses MBP protein levels (Fig. $8 B$ ).

Since Sox 17 promotes cell cycle exit and antagonizes Wnt $/ \beta$ catenin signaling, we hypothesized that Sox17 interaction with $\beta$-catenin may distinguish the two proliferative conditions. Immunoprecipitation assays with lysates of cultured OPCs showed that endogenous protein complexes containing $\beta$-catenin and Sox17 were present at much higher levels in PDGF alone than in PDGF + bFGF (Fig. 8C). This result indicates that, at the height of Sox17 expression, Sox17 binding could prevent $\beta$-catenin from stimulating cyclin D1 expression and thus contribute to the attenuation of cell cycle activity. To test the prediction that Sox17 would be associated with $\beta$-catenin under differentiating conditions, we performed further immunoprecipitation analysis of OPCs cultured for $3 \mathrm{~d}$ with PDGF and T3. These revealed the presence of Sox17 in $\beta$-catenin complexes from OPCs with T3, albeit at lower levels than in PDGF alone (Fig. 8D). The difference in the levels of catenin-bound Sox17 is consistent with the decline of Sox 17 on the third day of T3 treatment (Fig. 1D). Based on these findings, we hypothesized that the association between Sox17 and $\beta$-catenin could be most easily detected at a phase in WM development when cell proliferation has begun to decline. Immunoprecipitation experiments using WM tissue showed that $\beta$-catenin-Sox17 complexes were most readily detected at P18 (Fig. 8E). Conversely, in agreement with the pattern of Sox17
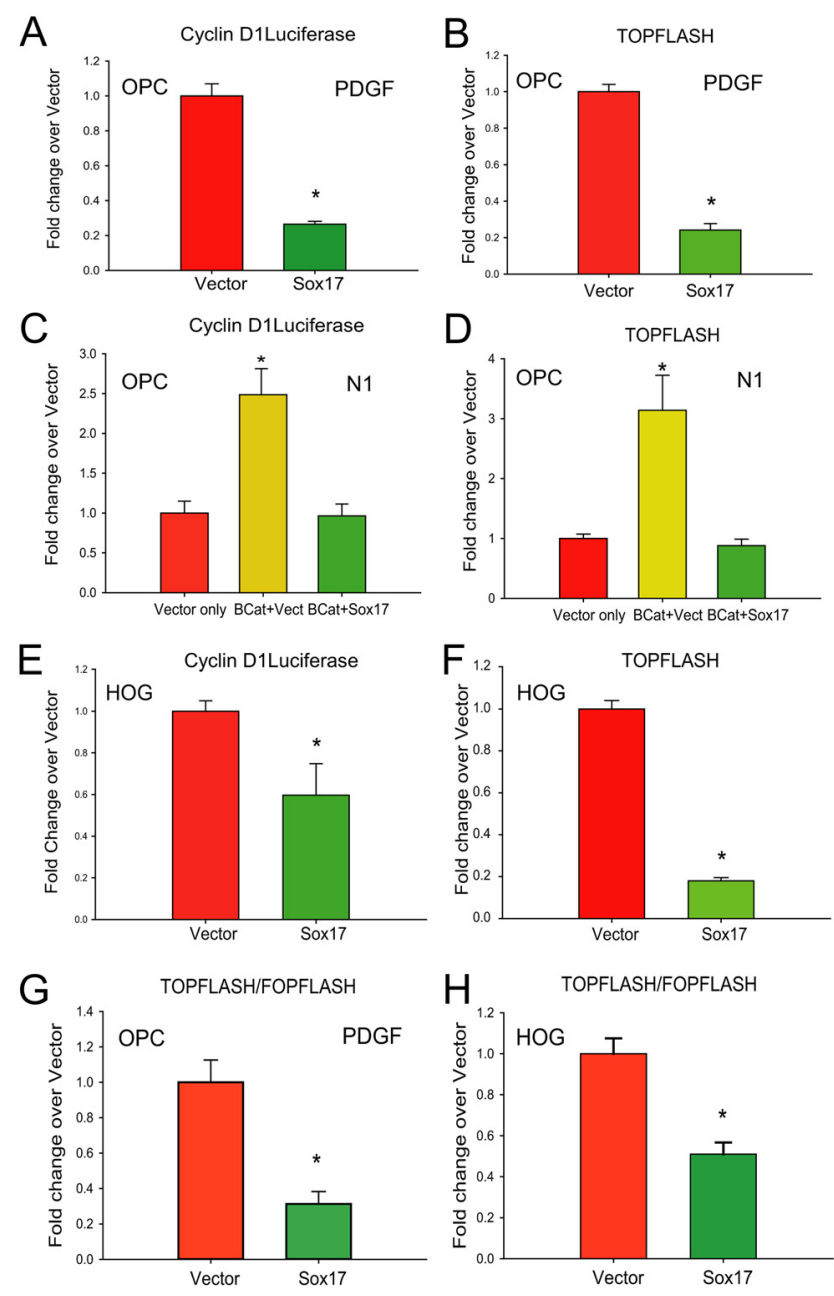

Figure 9. Sox17 represses cyclin D1 transcription in reporter assays. Primary OPCs maintained in PDGF were transiently transfected with cyclin D1-luciferase and vector (PCMVTnT) or Sox17. $A, C$, Cells were allowed to recover for $48 \mathrm{~h}$ in PDGF $(\boldsymbol{A})$ or N1 $(\boldsymbol{C})$ before assay. $\boldsymbol{B}$, Primary OPCs maintained in PDGF were transiently transfected with TOPFLASH reporter to assess TCF/ $\beta$-catenin transcriptional activity. Cells were allowed to recover for $48 \mathrm{~h}$ in PDGF. C, Sox17 represses cyclin D1 promoter activity in the presence of cotransfected $\beta$-catenin (BCat). C, D, OPCs cotransfected with TOPFLASH and BCat were allowed to recover in the absence of PDGF (N1). Equal amounts of Sox 17 and $\beta$-catenin expression plasmid were cotransfected in $\boldsymbol{C}$ and $\boldsymbol{D}$. E, HOG cells were transfected with cyclin D1-luciferase in N1 and allowed to recover in $10 \% \mathrm{FBS}$. $F$, HOG cells transfected with TOPFLASH showed suppression of reporter activity by Sox 17 similar to OPCs in B. G, Mean TOPFLASH/FOPFLASH luciferase activity ratios for primary OPCs transfected and maintained in PDGF as in $\boldsymbol{B}$. $\boldsymbol{H}$, TOPFLASH/FOPFLASH luciferase ratios for HOG cells transfected as in $\boldsymbol{F} .{ }^{*} p<0.01$ versus vector, Student's unpaired $t$ test. Vect, Vector.

expression in developing WM (Fig. 5), the levels of bound Sox17 at $\mathrm{P} 30$ were very low (Fig. $8 E$ ).

Since $\beta$-catenin functions as a transcription complex with T-cell transcription factor (TCF7L2/TCF4) and Sox17 interacts with $\beta$-catenin, we hypothesized that Sox 17 may also interact with TCF4. Interestingly, TCF4 levels were too low to be detected by Western blotting after immunoprecipitation with the anti- $\beta$ catenin antibody (data not shown), indicating that only a very small pool of $\beta$-catenin bound to TCF4 in WM. However, following enrichment by immunoprecipitation with an anti-TCF4 antibody, TCF4 was detected in lysates from P5 and P18 WM (Fig. 8 F). These immunoprecipitates contained both $\beta$-catenin and Sox17. At P30, however, like Sox17, TCF4 levels fell dramatically (Fig. $8 F$ ), so that $\beta$-catenin at this age is believed to bind very little TCF 4 or Sox 17 (Fig. $8 E, F$ ). These changes at P30 co- 

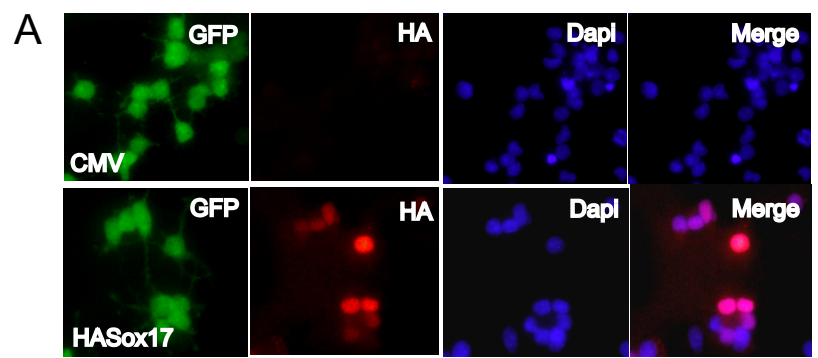

B

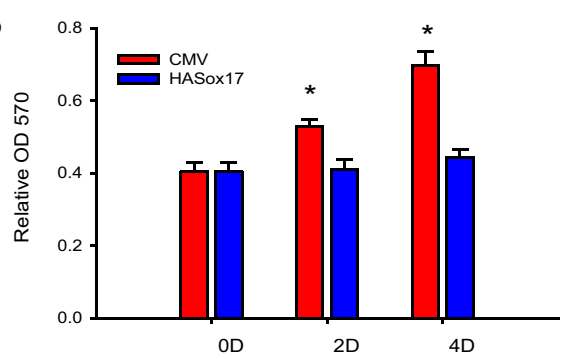

C

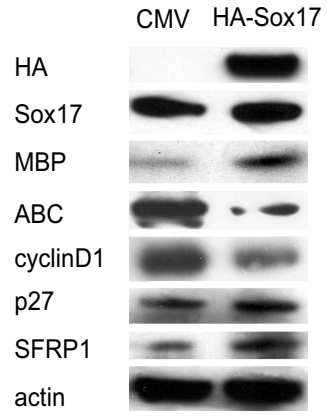

$$
\text { D }
$$

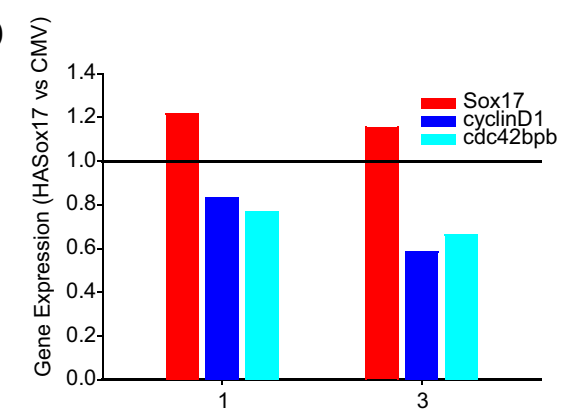

E

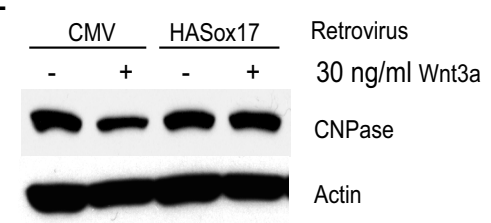

Figure 10. Retroviral Sox 17 expression regulates Wnt targets and inhibits cell growth. $A$, Primary OP(s maintained in PDGF plus bFGF for $1 \mathrm{~d}$ were transduced overnight with pMXs-CMV-HASox17Ires2ZsGreen (HASox17) retrovirus or pMXs-CMV-ZsGreen (CMV) control, both in green, and allowed to recover in PDGF plus bFGF for a further $3 \mathrm{~d}$. Immunofluorescence for the HA epitope tag (red) shows that recombinant Sox17 protein is nuclear in primary OPCs. Magnification, $400 \times . B$, MTT assay showing inhibition of OPC growth by Sox 17 retrovirus. Primary OPCs transduced with HASox17 retrovirus (blue bars) failed to show significant cell growth in the presence of PDGF plus bFGF. MTT reduction assays were performed before (OD), and at $2 \mathrm{~d}(2 \mathrm{D})$ or $4 \mathrm{~d}(4 \mathrm{D})$ after the addition of retroviral supernatant. ${ }^{*} p<0.05$, ANOVA, Tukey's test. $C$, Western blotting shows reduced levels of ABC, and cyclin D1, with enhanced MBP, p27, and SFRP1 expression following Sox17 overexpression with the HASox17 retrovirus. Transduced OPCs were allowed to recover for $3 \mathrm{~d}$ in $10 \mathrm{ng} / \mathrm{ml}$ PDGF plus bFGF. D, Quantitative real-time PCR assays showing the levels of Sox 17 , cdc $42 \mathrm{bpb}$, and cyclin D1 RNA at 1 and $3 \mathrm{~d}$ after retroviral transduction. OPCs were allowed to recover in PDGF plus bFGF. Data shown represent fold increase of RNA levels with HASox 17 over CMV control. $\boldsymbol{E}$, Western blotting analysis showing the inhibitory effect of Wnt3a on CNPase protein levels is abolished by Sox17. Primary OPCs maintained in PDGF were transduced with HAS ox 17 retrovirus overnight, followed by recovery in $\mathrm{N} 1$, in the absence or presence of $30 \mathrm{ng} / \mathrm{ml}$ Wnt3a for $2 \mathrm{~d}$.

incide with a further decline in cyclin D1 levels (Fig. 5B), providing in vivo evidence that the binding of Sox17 to $\beta$-catenin and TCF4 in developing WM plays an important role in OP cell cycle exit.

\section{Sox17 downregulates $\boldsymbol{\beta}$-catenin-induced cyclin D1 promoter activity}

Since the loss of Sox17 stimulates Wnt signaling, it can be predicted that its overexpression in OPCs would suppress Wnt activity. This was tested using reporters responsive to $\beta$-catenin/ TCF signaling. We predicted that high endogenous levels of $\beta$-catenin induced by PDGF would contribute to cyclin D1 expression, and that recombinant Sox17 should antagonize cyclin D1 and TOPFLASH reporter activities. In reporter assays performed in the presence of PDGF, Sox17 expression repressed the activities of the cyclin D1 promoter and TOPFLASH (Fig. 9A,B). In addition, we hypothesized that by lowering the levels of endogenous $\beta$-catenin using mitogen withdrawal, it might be possible to uncover the function of Sox17 on recombinant $\beta$-catenin. Indeed, Sox17 also suppressed $\beta$-catenin-activated cyclin D1 promoter activity (Fig. 9C) and TOPFLASH (Fig. 9D) under basal conditions (N1), indicating that in OPCs Sox 17 possesses the capacity to regulate Wnt-induced transcription mediated by $\beta$-catenin/TCF. In addition to primary OPCs, the function of Sox 17 was also tested in a HOG cell line in which constitutive autocrine Wnt signaling supports tumor cell growth. MTT assays indicated that the exogenous application of SFRP1 attenuated the growth of HOG cells by $\sim 30 \%$, whereas PDGF and Wnt3a had no effect (data not shown). Similar to proliferating OPCs maintained in PDGF, cotransfection with a Sox 17 plasmid also decreased cyclin $\mathrm{D} 1$ promoter and TOPFLASH activity in HOG cells (Fig. 9E,F). These results indicate that Sox17 likely regulates OPC development through modulating $\beta$-catenin/TCFmediated transcription of Wnt-induced genes, including cyclin D1. To exclude nonspecific effects with the TOPFLASH reporter, TOPFLASH reporter assays were performed together with FOPFLASH, which bears mutated TCF binding sites. In the presence of recombinant Sox17, significant decreases in TOPFLASH/ FOPFLASH ratios are observed in PDGFtreated primary OPCs (Fig. 9G) and HOG cells (Fig. 9H).

Sox17 overexpression inhibits mitogenstimulated OPC cell growth and decreases endogenous cyclin D1 RNA

To demonstrate that cell proliferation and $\mathrm{Wnt} / \beta$-catenin pathway regulation were the direct result of Sox 17 action, we performed a gain-of-function experiment by overexpressing recombinant Sox 17 in proliferating OPCs. This approach involved the use of a retroviral expression system, which is known to selectively target proliferating cells. A CMV promoter-driven, epitope-tagged retroviral expression construct, HA-Sox17-IRES-EGFP, was generated to facilitate high-efficiency transduction of primary OPCs. Expression of the recombinant Sox17 was detected exclusively in the nuclei of transduced proliferating OPCs (Fig. 10A) maintained in the presence of PDGF and bFGF. In these cells, recombinant Sox17 inhibits mitogen-stimulated cell growth, as measured by an MTT reduction assay performed over the course of $4 \mathrm{~d}$ (Fig. 10B). This effect is unlikely to be due to a net effect on cell death, as the total numbers of OPCs was not reduced when compared with the number measured at the beginning of the experiment (Fig. $10 B$ ).

To verify that the levels of endogenous $\beta$-catenin and cyclin D1 are modulated by Sox17 overexpression, Western blot analy- 
A

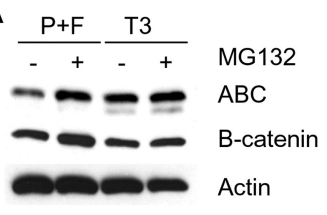

B

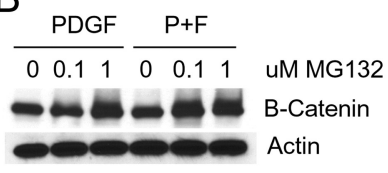

C CMV HASox17

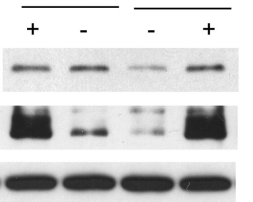

MG132

B-catenin

S37/33 P- B-Catenin

Actin

Figure 11. $\beta$-catenin turnover by the proteasome in proliferating OPCs is regulated by Sox17. $A$, Western blot showing the difference in proteasomal turnover of $\beta$-catenin between proliferating and differentiated OPCs. Cells were plated in N1+ PDGF + bFGF or N1 $+\mathrm{T} 3$ for $3 \mathrm{~d}$. Two micromolar MG132 was added during the final $4 \mathrm{~h}$ before analysis. $\boldsymbol{B}$, Western blot showing rapid turnover of $\beta$-catenin in proliferating OPCs. Primary OPCs treated with either PDGF or PDGF + bFGF for $3 \mathrm{~d}$ were exposed to increasing doses of MG132 during the final $6 \mathrm{~h}$ before analysis. C, MG132 blocks Sox17-mediated degradation of $\beta$-catenin. OPCs maintained in PDGF+ bFGF for $1 \mathrm{~d}$ were transduced with pMXs-CMV-HASox17Ires2ZsGreen (HASox17) retrovirus or pMXs-CMV-ZsGreen (CMV) control, as in Figure 10, and were allowed to recover in PDGF+ bFGF for $3 \mathrm{~d}$. Two micromolar MG132 was added during the final $4 \mathrm{~h}$ before analysis by Western blotting. D, MG132 blocks Sox17-mediated increase in CNPase levels. Primary OPCS were transduced and treated as in $C$, except that $1 \mu \mathrm{MMG} 132$ was added during the final $6 \mathrm{~h}$ of recovery in PDGF+ bFGF.

sis was performed using transduced OPC cultures. Our results confirm that $\mathrm{ABC}$ is reduced along with cyclin $\mathrm{D} 1$ protein in the presence of recombinant Sox17 (Fig. 10C). The protein levels of $\mathrm{MBP}$ and $\mathrm{p} 27 \mathrm{Kip} 1$ were also increased (Fig. 10C), indicating enhanced OPC differentiation. In agreement with the decrease in $\beta$-catenin levels, SFRP1 was also found to be increased following retroviral transduction. These changes in protein levels were also accompanied by alterations in cyclin D1 RNA (Fig. 10D), indicating that Sox 17 -mediated regulation of $\beta$-catenin activity leads to decreased endogenous cyclin D1 expression. In addition, cdc42bpb RNA levels also fell significantly below those of controls (Fig. 10D). Immunostaining of OPCs transduced with the retroviral constructs revealed that recombinant Sox17 reduced cdc42bpb detection in GFP-positive cells (to 60\% of total number of GFP cells in CMV controls; data not shown).

Since PDGF and Wnt3a decreased MBP levels (Fig. 6A), and Wnt3a (15-50 ng/ml) inhibited MBP, PLP, and CNP expression (Fig. 3B) (data not shown), we hypothesized that Sox17 may also relieve the repression of myelin protein expression. Interestingly, the overexpression of Sox17 prevented Wnt3a-induced downregulation of CNP protein levels (Fig. $10 \mathrm{E}$ ).

\section{Sox 17 promotes proteasomal degradation of $\boldsymbol{\beta}$-catenin}

The ubiquitin-proteasome system is the major pathway for the targeted degradation of many proteins, including $\beta$-catenin (Aberle et al., 1997), in mitotic cells (Glickman and Ciechanover, 2002). We used the cell-permeable proteasome inhibitor MG132 to study $\beta$-catenin turnover in proliferating and differentiating OPCs and to determine the role of Sox 17 in its regulation. Figure $11 A$ shows that proteasomal degradation of $\mathrm{ABC}$ and $\beta$-catenin occurs at a significantly greater rate in proliferating OPCs $(\mathrm{P}+\mathrm{F})$ than in differentiated cells (T3). Such significant differences were not observed between the proliferating conditions of PDGF and PDGF plus bFGF (Fig. $11 B$ ). Sox 17 levels did not change with the addition of MG132 (data not shown), suggesting that its turnover was not readily detected under these conditions. Our results in
Figure $10 C$ demonstrated that retroviral Sox17 induced a clear decrease in $\mathrm{ABC}$ levels. To determine whether Sox17 also regulated total cellular $\beta$-catenin levels via the proteasome, we transduced primary OPCs with the same retroviral expression constructs as shown in Figure 10, and maintained the cells in PDGF plus bFGF for $3 \mathrm{~d}$. Figure $11 C$ shows that recombinant HASox17 reduced the levels of $\beta$-catenin and Ser37/Ser33 P- $\beta$ catenin compared with control vector. This is in agreement with increased Ser37/Ser33 P- $\beta$-catenin after Sox17 knockdown shown in Figure $2 D$, suggesting that Sox 17 regulates multiple forms of $\beta$-catenin. Inhibition of proteasome activity with MG132 abolished the Sox17-mediated decrease in $\beta$-catenin levels (Fig. 11C). Interestingly, the Sox 17-induced regulation of CNPase levels was also abolished by MG132 (Fig. 11D), indicating that myelin protein regulation by Sox 17 is also proteasome dependent. In summary, our findings support a function for Sox17 in the control of progenitor cell proliferation and gene expression through the modulation of canonical $\mathrm{Wnt} / \beta$-catenin signaling during the development of the oligodendrocyte lineage.

\section{Discussion}

In this study, we define a major signal transduction pathway associated with Sox transcription factor function in oligodendrocyte development. Through loss-of-function screening to identify genes and pathways that lie downstream of Sox17, we have revealed a role for Sox17 in the modulation of the $\mathrm{Wnt} / \beta$-catenin signaling in the oligodendrocyte lineage. We observed that crucial elements of this pathway mediate growth factor responses in OPCs that are antagonized by Sox17. In addition, the developmental regulation of Sox17 expression of Wnt $/ \beta$-catenin signaling components, and Sox $17 / \beta$-catenin complexes in white matter tissue are consistent with a role in postnatal oligodendrocyte development in vivo.

We previously demonstrated that Sox 17 regulates cell cycle exit and initiation of differentiation in OPCs (Sohn et al., 2006). We now show that Sox17 expression correlates with the decline of proliferative activity and $\beta$-catenin levels in OPCs and WM, while attenuation of Sox17 levels in vitro and in Sox17 mutant mice upregulates cyclin D1 expression levels. These findings are consistent with the current view of Wnt signaling in oligodendrocyte development: unrestricted Wnt- $\beta$-catenin activation prevents OPC differentiation, as well as remyelination after demyelination (Shimizu et al., 2005; Feigenson et al., 2009). Furthermore, Wnt pathway proteins are enhanced in multiple sclerosis lesions, revealing pathological consequences of Wnt dysregulation (Fancy et al., 2009). We have shown that overexpressing recombinant Sox17 and interference with Sox17mediated $\beta$-catenin degradation regulates CNPase levels. Studies in progress in our laboratory will further characterize Sox17 mutant and transgenic mouse lines, and determine the relationship between Sox17 expression and Wnt signaling in oligodendrocyte lineage cells in animal models of demyelination.

Our studies indicate that cyclin D1 provides a useful read-out of the effects of Sox 17 manipulation on Wnt $/ \beta$-catenin signaling (Shtutman et al., 1999; Tetsu and McCormick, 1999). In developing white matter, downregulation of cyclin D1 is temporally coincident with the peak of Sox17 expression, and occurs at a developmental stage corresponding to oligodendrocyte differentiation and myelination. Cyclin D1 expression is rapidly downregulated during OPC differentiation in the presence of T3, which also accelerates the peak and decline of Sox17 levels, and strongly reduces OPC proliferation (Baas et al., 1997). In cultured OPCs and in white matter tissue of mutant mice, knockdown or 
targeted ablation of Sox17 leads to increased cyclin D1 gene expression. Our results with cyclin D1 thus contrast with the studies of Sinner et al. (2007), where Sox17 siRNA failed to produce significant changes in cyclin D1 and myc RNA and proliferation in colon carcinoma cells. Nonetheless, Sox17 overexpression still suppressed the formation of puromycin-resistant colonies (Sinner et al., 2007).

Sox proteins are thought to possess dual mechanisms of action-targeting of gene activation and regulation of the Wnt pathway (Takash et al., 2001; Kormish et al., 2010). Sox6 (Iguchi et al., 2007) and Sox1 (Kan et al., 2004) both interact with $\beta$-catenin and repress proliferation, while stimulating the expression of differentiation markers. In cultured OPCs, Sox17 performs both functions: downregulation of $\beta$-catenin levels and transcriptional activity (present study); and stimulation of myelin gene expression (Sohn et al., 2006). However, the maintenance of proliferation does not always prevent cells from differentiating (Dyer and Cepko, 2000). Sox 5 causes premature cell cycle exit in neural progenitor cells in the chick spinal cord, but also prevents differentiation (Martinez-Morales et al., 2010). Although we have shown that Sox17 regulates the promoters of myelin genes (Sohn et al., 2006), other components of the pathway (e.g., p27Cip/Kip) that are modulated by Sox17, and are important for both cell cycle regulation and expression of myelin proteins, also play important roles in differentiation.

The antagonism of $\mathrm{Wnt} / \beta$-catenin signaling by Sox17 in the oligodendrocyte lineage raises the question of stimulatory signals that converge upon the canonical Wnt/ $\beta$-catenin pathway in the developing WM. Recently, mammalian target of rapamycin and Akt have been shown to be crucial for maturation of the OPC (Flores et al., 2008; Narayanan et al., 2009; Tyler et al., 2009), and $\beta$-catenin was shown to be an integral downstream factor in the PI3-Akt-GSK3 $\beta$ pathway in mediating the effects of IGF-1 (Ye et al., 2010). Cross talk between WNT and FGF signaling has also been described (Katoh and Katoh, 2006). Our present studies support the hypothesis that $\beta$-catenin is involved in mediating the induction of cyclin D1 expression by PDGF. Regulation of $\mathrm{ABC}$ may arise from tyrosine kinase regulation of $\beta$-catenin pools (Müller et al., 1999) or may be a consequence of enhanced $\beta$-catenin translation through $S r c$ tyrosine kinase activity (Karni et al., 2005; Shah and Vincent, 2005). PDGF likely activates multiple kinase pathways-MEK/LRP6 (Fig. 7) and PI3K/Akt/ GSK3 $\beta$ (DeMali et al., 1997; Taylor, 2000; Nunes et al., 2008)—in the activation of $\beta$-catenin, cyclin D1, and cell proliferation in OPCs. In addition, the effects of PDGF on $\beta$-catenin may also be mediated via p68 RNA helicase, which, when phosphorylated, is present in complexes assembled at the cyclin D1 promoter (Yang et al., 2006, 2007). Further work will be needed address the role of Sox17 function in other signaling networks regulating cateninregulated transcription.

We have examined the effect of T3 and bFGF on cell cycle properties in relation to $\beta$-catenin interaction and observed that the binding of Sox17 to $\beta$-catenin is supported by T3 and abolished by bFGF. These studies were performed in the presence of PDGF, which, in addition to promoting $\beta$-catenin accumulation, also supports high levels of Sox17 expression (Sohn et al., 2006). The selective absence of Sox17-containing $\beta$-catenin complexes after exposure to bFGF, which prevents OPC differentiation (Baron et al., 2000), implicates direct protein-protein binding as part of the molecular mechanism for Sox 17 function during oligodendrocyte differentiation. Our loss-of-function and gain-offunction studies indicate that the levels of $\mathrm{ABC}$ protein and total $\beta$-catenin are significantly altered by Sox 17 , suggesting that complex formation is involved in regulating $\beta$-catenin abundance.

In colon carcinoma cells, Sox 17 interacts with both $\beta$-catenin and TCF/lymphoid enhancer factor members via its HMG domain (Sinner et al., 2007), leading to the degradation of both of these proteins. This is believed to be independent of GSK3 $\beta$ activity, as Sox17-mediated degradation of $\beta$-catenin was unaffected by lithium chloride (Sinner et al., 2007). We were unable to detect endogenous $\beta$-catenin-TCF4 complexes in mitogentreated cultured OPCs (data not shown); however, the presence of Sox17 in P5 and P18 WM immunoprecipitates containing $\beta$-catenin and TCF4 supports the existence of a tripartite complex that has been described for recombinant Sox17 (Sinner et al., 2007). That this interaction with Sox 17 precedes the proteasomal degradation of $\beta$-catenin (Sinner et al., 2007) is supported by the decline in the total levels of $\beta$-catenin and ABC in P18 WM (Fig. $5)$. Furthermore, in agreement with a recent report of histone deacetylase 1 (HDAC1) competing with $\beta$-catenin to bind TCF4 (Ye et al., 2009), HDAC1 was not found in immunoprecipitates with $\beta$-catenin, either in cultured OPCs or in WM tissue (data not shown).

Our experiments with MG132 demonstrate that Sox17 promotes proteasomal degradation of $\beta$-catenin in proliferating OPCs. It is possible that, through modulating total cellular $\beta$-catenin levels, Sox17 indirectly alters the intracellular distribution of $\beta$-catenin. Because of its nuclear localization (Fig. $10 A)$, it would be reasonable to predict that depletion of $\beta$-catenin by Sox 17 occurs primarily from the nucleus. In addition, the higher rate of $\beta$-catenin turnover in progenitor cells compared with differentiated cells (Fig. 11A) is consistent with a proteasome-dependent function for Sox 17, whose expression is more readily detectable in immature OPCs than in differentiated oligodendrocytes.

Although our emphasis was on the canonical Wnt $\beta$-catenin pathway, other Sox17-regulated genes identified in the microarray screen also warrant investigation into their roles in OPC morphogenesis and/or migration - properties shown to be strongly mediated by PDGF (Finzsch et al., 2008; Miyamoto et al., 2008; Frost et al., 2009). Wnt ligands activate the planar cell polarity signaling pathway to control cell movement and polarity through cascades including RhoA and Jun terminal kinase (or MAPK10). Our analysis shows that Sox17 modulated PAK1, which itself is known to modulate the $\beta$-catenin pathway (He et al., 2008). PAK and cdc42 binding protein kinase (also known as MRCK $\alpha / \beta$ ) are both effectors of cdc42, sharing CRIB (Cdc42-Rac-interactive binding) motifs (Cotteret and Chernoff, 2002). PAK functions in the control of polarity in migration (Nagel et al., 2009), while cdc42 binding protein kinases are known to be involved in actin reorganization (Leung et al., 1998; Wilkinson et al., 2005). It is not yet clear how these proteins function in OPC development. There is evidence that cell polarity proteins such as PAK can function in mitotic exit (Höfken and Schiebel, 2002); however, the combined ablation of cdc42 and Racl in the oligodendroglial lineage did not affect either proliferation or differentiation of OPCs, but instead regulated myelin sheath formation (Thurnherr et al., 2006).

In conclusion, our study identifies molecular interactions between Sox17 and the Wnt/ $\beta$-catenin pathway during oligodendrocyte development, and demonstrates Sox 17 repression of $\beta$-catenin levels and transcriptional activity. As the $\mathrm{Wnt} / \beta$ catenin pathway is involved in oligodendrocyte maturation and pathology (Fancy et al., 2009), further analysis of multiple arms of the Wnt pathway regulated by Sox17 will elucidate crucial 
molecular events underlying developmental transitions in oligodendrocyte development and disease.

\section{References}

Aberle H, Bauer A, Stappert J, Kispert A, Kemler R (1997) $\beta$-catenin is a target for the ubiquitin-proteasome pathway. EMBO J 16:3797-3804.

Baas D, Bourbeau D, Sarliève LL, Ittel ME, Dussault JH, Puymirat J (1997) Oligodendrocyte maturation and progenitor cell proliferation are independently regulated by thyroid hormone. Glia 19:324-332.

Bahnassy AA, Zekri AR, El-Houssini S, El-Shehaby AM, Mahmoud MR, Abdallah S, El-Serafi M (2004) Cyclin A and cyclinD1 as significant prognostic markers in colorectal cancer patients. BMC Gastroenterol 4:22.

Bakay M, Zhao P, Chen J, Hoffman EP (2002) A web-accessible complete transcriptome of normal and DMD muscle. Neuromuscul Disord 12 [Suppl 1]:S125-S141.

Baron W, Metz B, Bansal R, Hoekstra D, de Vries H (2000) PDGF and FGF-2 signaling in oligodendrocyte progenitor cells: regulation of proliferation and differentiation by multiple intracellular signaling pathways. Mol Cell Neurosci 15:314-329.

Baumann N, Pham-Dinh D (2001) Biology of oligodendrocyte and myelin in the mammalian central nervous system. Physiol Rev 81:871-927.

Belachew S, Aguirre AA, Wang H, Vautier F, Yuan X, Anderson S, Kirby M, Gallo V (2002) Cyclin-dependent kinase-2 controls oligodendrocyte progenitor cell cycle progression and is down-regulated in adult oligodendrocyte progenitors. J Neurosci 22:8553-8562.

Casaccia-Bonnefil P, Liu A (2003) Relationship between cell cycle molecules and onset of oligodendrocyte differentiation. J Neurosci Res 72:1-11.

Casaccia-Bonnefil P, Hardy RJ, Teng KK, Levine JM, Koff A, Chao MV (1999) Loss of p27Kip1 function results in increased proliferative capacity of oligodendrocyte progenitors but unaltered timing of differentiation. Development 126:4027-4037.

Červenka I, Wolf J, Mašek J, Krejci P, Wilcox WR, Kozubík A, Schulte G, Gutkind JS, Bryja V (2011) Mitogen-activated protein kinases promote WNT/ $\beta$-catenin signaling via phosphorylation of LRP6. Mol Cell Biol $31: 179-189$

Chen YW, Zhao P, Borup R, Hoffman EP (2000) Expression profiling in the muscular dystrophies: identification of novel aspects of molecular pathophysiology. J Cell Biol 151:1321-1336.

Chew LJ, Coley W, Cheng Y, Gallo V (2010) Mechanisms of regulation of oligodendrocyte development by p38 mitogen-activated protein kinase. J Neurosci 30:11011-11027.

Cotteret S, Chernoff J (2002) The evolutionary history of effectors downstream of Cdc42 and Rac. Genome Biol 3:REVIEWS0002.

DeMali KA, Whiteford CC, Ulug ET, Kazlauskas A (1997) Platelet-derived growth factor-dependent cellular transformation requires either phospholipase Cgamma or phosphatidylinositol 3 kinase. J Biol Chem 272:9011-9018.

Dyer MA, Cepko CL (2000) p57(Kip2) regulates progenitor cell proliferation and amacrine interneuron development in the mouse retina. Development 127:3593-3605.

Etxeberria A, Mangin JM, Aguirre A, Gallo V (2010) Adult-born SVZ progenitors receive transient synapses during remyelination in corpus callosum. Nat Neurosci 13:287-289.

Fancy SP, Baranzini SE, Zhao C, Yuk DI, Irvine KA, Kaing S, Sanai N, Franklin RJ, Rowitch DH (2009) Dysregulation of the Wnt pathway inhibits timely myelination and remyelination in the mammalian CNS. Genes and Development 23:1571-1585.

Feigenson K, Reid M, See J, Crenshaw EB 3rd, Grinspan JB (2009) Wnt signaling is sufficient to perturb oligodendrocyte maturation. Mol Cell Neurosci 42:255-265.

Finzsch M, Stolt CC, Lommes P, Wegner M (2008) Sox9 and Sox10 influence survival and migration of oligodendrocyte precursors in the spinal cord by regulating PDGF receptor alpha expression. Development 135:637-646.

Fischer AN, Fuchs E, Mikula M, Huber H, Beug H, Mikulits W (2007) PDGF essentially links TGF-beta signaling to nuclear beta-catenin accumulation in hepatocellular carcinoma progression. Oncogene 26:3395-3405.

Flores AI, Narayanan SP, Morse EN, Shick HE, Yin X, Kidd G, Avila RL, Kirschner DA, Macklin WB (2008) Constitutively active Akt iniduces enhanced myelination in the CNS. J Neurosci 28:7174-7183.
Frame S, Cohen P (2001) GSK3 takes centre stage more than 20 years after its discovery. Biochem J 359:1-16.

Frost EE, Zhou Z, Krasnesky K, Armstrong RC (2009) Initiation of oligodendrocyte progenitor cell migration by a PDGF-A activated extracelliular regulated kinase (ERK) signaling pathway. Neurochem Res 34: $169-181$.

Ghiani C, Gallo V (2001) Inhibition of cyclin E-cylin-dependent kinase 2 complex formation and activity is associated with cell cycle arrest and withdrawal in oligodendrocyte progenitor cells. J Neurosci 21:1274-1282.

Ghiani CA, Eisen AM, Yuan X, DePinho RA, McBain CJ, Gallo V (1999a) Neurotransmitter receptor activation triggers p27(Kip1) and p21(CIP1) accumulation and G1 cell cycle arrest in oligodendrocyte progenitors. Development 126:1077-1090.

Ghiani CA, Yuan X, Eisen AM, Knutson PL, DePinho RA, McBain CJ, Gallo V (1999b) Voltage-activated $\mathrm{K}^{+}$channels and membrane depolarization regulate accumulation of the cyclin-dependent kinase inhibitors $\mathrm{p} 27^{\mathrm{Kip} 1}$ and $\mathrm{p} 21^{\mathrm{CIP} 1}$ in glial progenitor cells. J Neurosci 19:5380-5392.

Glickman MH, Ciechanover A (2002) The ubiquitin-proteasome proteolytic pathway: destruction for the sake of construction. Physiol Rev 82:373-428.

Gubbay J, Collignon J, Koopman P, Capel B, Economou A, Münsterberg A, Vivian N, Goodfellow P, Lovell-Badge R (1990) A gene mapping to the sex-determining region of the mouse $\mathrm{Y}$ chromosome is a member of a novel family of embryonically expressed genes. Nature 346:245-250.

$\mathrm{He} \mathrm{H}$, Shulkes A, Baldwin GS (2008) PAK1 interacts with $\beta$-catenin and is required for the regulation of the $\beta$-catenin signalling pathway by gastrins. Biochem Biophys Acta 1783:1943-1954.

Höfken T, Schiebel E (2002) A role for cell polarity proteins in mitotic exit. EMBO J 21:4851-4862.

Hudson C, Clements D, Friday RV, Stott D, Woodland HR (1997) XSox17alpha and -beta mediate endoderm formation in Xenopus. Cell 91:397-405.

Iguchi H, Urashima Y, Inagaki Y, Ikeda Y, Okamura M, Tanaka T, Uchida A, Yamamoto TT, Kodama T, Sakai J (2007) Sox6 suppresses cyclin D1 promoter activity by interacting with $\beta$-catenin and histone deacetylase 1 ,and its down-regulation induces pancreatic beta-cell proliferation. J Biol Chem 282:19052-19061.

Kalani MY, Cheshier SH, Cord BJ, Bababeygy SR, Vogel H, Weissman IL, Palmer TD, Nusse R (2008) Wnt-mediated self-renewal of neural stem/ progenitor cells. Proc Natl Acad Sci U S A 105:16970-16975.

Karni R, Gus Y, Dor Y, Meyuhas O, Levitzki A (2005) Active Src elevates the expression of $\beta$-catenin by enhancement of cap-dependent translation. Mol Cell Biol 25:5031-5039.

Kanai-Azuma M, Kanai Y, Gad JM, Tajima Y, Taya C, Kurohmaru M, Sanai Y, Yonekawa H, Yazaki K, Tam PP, Hayashi Y (2002) Depletion of definitive gut endoderm in Sox17-null mutant mice. Development 129:2367-2379.

Kan L, Israsena N, Zhang Z, Hu M, Zhao LR, Jalali A, Sahni V, Kessler JA (2004) Sox1 acts through multiple independent pathways to promote neurogenesis. Developmental Biology 269:580-594.

Katoh M, Katoh M (2006) Cross-talk of WNT and FGF signaling pathways at GSK3beta to regulate $\beta$-catenin and SNAIL signaling cascades. Cancer Biol Ther 5:1059-1064.

Kim I, Saunders TL, Morrison SJ (2007) Sox17 dependence distinguishes the transcriptional regulation of fetal from adult hematopoietic stem cells. Cell 130:470-483.

Kormish JD, Sinner D, Zorn AM (2010) Interactions between SOX factors and $\mathrm{Wnt} / \beta$-catenin signaling in development and disease. Dev Dyn 239:56-68.

Lappe-Siefke C, Goebbels S, Gravel M, Nicksch E, Lee J, Braun PE, Griffiths IR, Nave KA (2003) Disruption of CNP1 uncouples oligodendroglial functions in axonal support and myelination. Nat Genet 33:366-374.

Leung T, Chen XQ, Tan I, Manser E, Lim L (1998) Myotonic dystrophy kinase-related Cdc42-binding kinase acts as a cdc42-effector in promoting cytoskeletal reorganization. Mol Cell Biol 18:130-140.

Levine JM, Reynolds R, Fawcett JW (2001) The oligodendrocyte precursor cell in health and disease. Trends Neurosci 24:39-47.

Liu C, Li Y, Semenov M, Han C, Baeg GH, Tan Y, Zhang Z, Lin X, He X (2002) Control of $\beta$-catenin phosphorylation/degradation by a dualkinase mechanism. Cell 108:837-847. 
MacDonald BT, Tamai K, He X (2009) Wnt/ $\beta$-catenin signaling: components, mechanisms and diseases. Dev Cell 17:9-26.

Martinez-Morales PL, Quiroga AC, Barbas JA, Morales AV (2010) Sox5 controls cell cycle progression in neural progenitors by interfering with the WNT- $\beta$-catenin pathway. EMBO Rep 11:466-472.

Matsui T, Kanai-Azuma M, Hara K, Matoba S, Hiramatsu R, Kawakami H, Kurohmaru M, Koopman P, Kanai Y (2006) Redundant roles of Sox17 and Sox18 in postnatal angiogenesis in mice. J Cell Sci 119:3513-3526.

McCarthy KD, de Vellis J (1980) Preparation of separate astroglial and oligodendroglial from rat cerebral tissue. J Cell Biol 85:890-902.

Miyamoto Y, Yamauchi J, Tanoue A (2008) Cdk5 phosphorylation of WAVE2 regulates oligodendrocyte precursor cell migration through nonreceptor tyrosine kinase Fyn. J Neurosci 28:8326-8337.

Müller T, Choidas A, Reichmann E, Ullrich A (1999) Phosphorylation and free pool of $\beta$-catenin are regulated by tyrosine kinases and tyrosine phosphatases during epithelial cell migration. J Biol Chem 274:10173-10183.

Nagel M, Luu O, Bisson N, Macanovic B, Moss T, Winklbauer R (2009) Role of p21-activated kinase in cell polarity and directional mesendoderm migration in the Xenopus Gastrula. Dev Dyn 238:1709-1726.

Narayanan SP, Flores AI, Wang F, Macklin WB (2009) Akt signals through the mammalian target of rapamycin pathway to regulate CNS myelination. J Neurosci 29:6860-6870.

Nunes RO, Schmidt M, Dueck G, Baarsma H, Halayko AJ, Kerstjens HA, Meurs H, Gosens R (2008) GSK-3/ $\beta$-catenin signaling axis in airway smooth muscle: role in mitogenic signaling. Am J Physiol Lung Cell Mol Physiol 294:L1110-L1118.

Piao S, Lee SH, Kim H, Yum S, Stamos JL, Xu Y, Lee SJ, Lee J, Oh S, Han JK, Park BJ, Weis WI, Ha NC (2008) Direct inhibition of GSK3beta by the phosphorylated cytoplasmic domain of LRP6 in Wnt/ $\beta$-catenin signaling. PLoS One 3:e4046.

Porlan E, Vidaurre OG, Rodríguez-Peña A (2008) Thyroid hormone receptor betal impairs cell proliferation by the transcriptional inhibition of cyclins D1, E and A2. Oncogene 27:2795-2800.

Post GR, Dawson G (1992) Characterization of a cell line derived from a human oligodendroglioma. Mol Chem Neuropathol 16:303-317.

Schepers GE, Teasdale RD, Koopman P (2002) Twenty pairs of Sox: extent, homology, and nomenclature of the mouse and human Sox transcription factor gene families. Dev Cell 3:167-170.

Seo J, Hoffman EP (2006) Prove set algorithms: is there a rational best bet? BMC Bioinformatics 7:395-407.

Shah K, Vincent F (2005) Divergent roles of c-Src in controlling plateletderived growth factor-dependent signaling in fibroblasts. Mol Biol Cell 16:5418-5432.

Shimizu T, Kagawa T, Wada T, Muroyama Y, Takada S, Ikenaka K (2005) Wnt signaling controls the timing of oligodendrocyte development in the spinal cord. Dev Biol 282:397-410.

Shtutman M, Zhurinsky J, Simcha I, Albanese C, D'Amico M, Pestell R, Ben-Ze'ev A (1999) The cyclin D1 gene is a target of the $\beta$-catenin/ LEF-1 pathway. Proc Natl Acad Sci U S A 96:5522-5527.

Sinner D, Rankin S, Lee M, Zorn AM (2004) Sox 17 and $\beta$-catenin cooperate to regulate the transcription of endodermal genes. Development 131: $3069-3080$

Sinner D, Kordich JJ, Spence JR, Opoka R, Rankin S, Lin SC, Jonatan D, Zorn AM, Wells JM (2007) Sox 17 and Sox4 differentially regulate $\beta$-catenin/ T-cell factor activity and proliferation of colon carcinoma cells. Mol Cell Biol 27:7802-7815.

Sohn J, Natale J, Chew LJ, Belachew S, Cheng Y, Aguirre A, Lytle J, NaitOumesmar B, Kerninon C, Kanai-Azuma M, Kanai Y, Gallo V (2006) Identification of Sox17 as a transcription factor that regulates oligodendrocyte development. J Neurosci 26:9722-9735.

Stolt CC, Lommes P, Friedrich RP, Wegner M (2004) Transcription factors Sox8 and Sox10 perform non-equivalent roles during oligodendrocyte development despite functional redundancy. Development 131:23492358.

Stolt CC, Schlierf A, Lommes P, Hillgärtner S, Werner T, Kosian T, Sock E, Kessaris N, Richardson WD, Lefebvre V, Wegner M (2006) SoxD proteins influence multiple stages of oligodendrocyte development and modulate SoxE protein function. Dev Cell 11:697-709.

Su Y, Shrubsole MJ, Ness RM, Cai Q, Kataoka N, Washington K, Zheng W (2006) Immunohistochemical expression of Ki-67, cyclinD1, $\beta$-catenin, cyclooxygenaase- 2 and epidermal growth factor receptor in human colorectal adenoma: a validation study of tissue microarrays. Cancer Epidemiol Biomarkers Prev 15:1719-1726.

Sun J, Khalid S, Rozakis-Adcock M, Fantus IG, Jin T (2009) P-21-activated protein kinase- 1 functions as a linker between insulin and Wnt signaling pathways in the intestine. Oncogene 28:3132-3144.

Takash W, Cañizares J, Bonneaud N, Poulat F, Mattéi MG, Jay P, Berta P (2001) Sox7 transcription factor: sequence, chromosomal localisation, expression, transactivation and interference with Wnt signaling. Nucleic Acids Res 29:4274-4283.

Tamai K, Semenov M, Kato Y, Spokony R, Liu C, Katsuyama Y, Hess F, Saint-Jeannet JP, He X (2000) LDL-receptor-related proteins in Wnt signal transduction. Nature 407:530-535.

Taylor CC (2000) Platelet-derived growth factor activates porcine thecal cell phosphatidylinositol-3-kinase-Akt/PKB and ras-extracellular signalregulated kinase-1/2 kinase signaling pathways via the platelet-derived growth factor-beta receptor. Endocrinology 141:1545-1553.

Tetsu O, McCormick F (1999) $\beta$-catenin regulates expression of cyclin D1 in colon carcinoma cells. Nature 398:422-426.

Thurnherr T, Benninger Y, Wu X, Chrostek A, Krause SM, Nave KA, Franklin RJ, Brakebusch C, Suter U, Relvas JB (2006) Cdc42 and Rac1 signaling are both required for and act synergistically in the correct formation of myelin sheaths in the CNS. J Neurosci 26:10110-10119.

Tyler WA, Gangoli N, Gokina P, Kim HA, Covey M, Levison SW, Wood TL (2009) Activation of the mammalian target of rapamycin (mTOR) is essential for oligodendrocyte differentiation. J Neurosci 29:6367-6378.

Wegner M (2000) Transcriptional control in myelinating glia: flavors and spices. Glia 31:1-14.

Wegner M (2001) Expression of Transcription Factors during oligodendroglial development. Microsc Res Tech 52:746-752.

Wissmüller S, Kosian T, Wolf M, Finzsch M, Wegner M (2006) The highmobility-group domain of Sox proteins interacts with DNA-binding domains of many transcription factors. Nucleic Acids Res 34:1735-1744.

Wilkinson S, Paterson HF, Marshall CJ (2005) Cdc42-MRCK and RhoROCK signalling cooperate in myosin phosphorylation and cell invasion. Nat Cell Biol 7:255-261.

Yang L, Lin C, Liu ZR (2006) p68 RNA helicase mediates PDGF-induced epithelial mesenchymal transition by displacing axin from $\beta$-catenin. Cell 127:139-155.

Yang L, Lin C, Zhao S, Wang H, Liu ZR (2007) Phosphorylation of p68 RNA helicase plays a role in platelet-derived growth factor-induced cell proliferation by up-regulating cyclinD1 and c-Myc expression. J Biol Chem 282:16811-16819.

Yasunaga M, Tada S, Torikai-Nishikawa S, Nakano Y, Okada M, Jakt LM, Nishikawa S, Chiba T, Era T, Nishikawa S (2005) Induction and monitoring of definitive and visceral endoderm differentiation of mouse ES cells. Nat Biotechnol 23:1542-1550.

Ye F, Chen Y, Hoang T, Montgomery RL, Zhao XH, Bu H, Hu T, Taketo MM, van Es JH, Clevers H, Hsieh J, Bassel-Duby R, Olson EN, Lu QR (2009) HDAC1 and HDAC2 regulate oligodendrocyte differentiation by disrupting the $\beta$-catenin-TCF interaction. Nat Neurosci 12:829-838.

Ye P, Hu Q, Liu H, Yan Y, D'ercole AJ (2010) $\beta$-catenin mediates insulinlike growth factor-1 actions to promote cyclinD1 mRNA expression, cell proliferation and survival in oligodendroglial cultures. Glia 58:10311041. 